\title{
Evaluation of the ERA-40 Surface Water Budget and Surface Temperature for the Mackenzie River Basin
}

\author{
Alan K. Betts And John H. Ball \\ Atmospheric Research, Pittsford, Vermont \\ PEDRO Viterbo \\ ECMWF, Reading, Berkshire, United Kingdom
}

(Manuscript received 29 January 2003, in final form 20 May 2003)

\begin{abstract}
The systematic biases in temperature and precipitation, and the surface water budget of European Centre for Medium-Range Weather Forecasts (ECMWF) 40-yr reanalysis (ERA-40) for the Mackenzie River basin are assessed by comparing monthly averages from ERA- 40 with basin averages of surface observations of temperature, precipitation, evaporation, and streamflow from the Mackenzie Global Energy and Water Cycle Experiment (GEWEX) Study (MAGS). The bias and spinup of precipitation in ERA-40 changes significantly over the analysis period. On an annual basis, both precipitation bias and spinup are correlated with the analysis increment of atmospheric total column water vapor. ERA-40 has, in addition, a high bias of precipitation in spring and a low bias in fall. The monthly precipitation analysis is best for the most recent decade, when the bias of the 0-12-h forecast precipitation is only a few percent higher than the MAGS observations, and ERA40 represents rather well the variability of monthly precipitation. Annual evapotranspiration from ERA-40 is higher than a MAGS estimate by $30 \%$. The annual runoff in ERA-40 is comparable to the annual streamflow, but the interannual variability is poorly correlated. ERA-40 has two runoff peaks: in April, when snowmelt runs off quickly over the frozen ground, and in August, when the lowest model layer melts and reaches a soil moisture threshold, when deep drainage increases rapidly. In the model liquid water budget, the soil water analysis increment contributes only $17 \mathrm{~mm}$ of water to the annual liquid budget (primarily in summer), which is small compared with the mean rainfall $(323 \mathrm{~mm})$ and snowmelt $(194 \mathrm{~mm})$. However, in the frozen budget, the analysis increment of snow water equivalent, with an annual mean total of $97 \mathrm{~mm}$, is not much smaller than the mean annual snowfall $(140 \mathrm{~mm})$. Improvements to the model snow treatment are needed: snow melts too soon in the model, and is replaced by the snow analysis increments. For the Mackenzie River, ERA-40 has a distinct seasonal temperature bias, with a $2-3-\mathrm{K}$ warm bias from December to April, and a cool bias in summer, reaching -1.5 $\mathrm{K}$ in July. This signal is larger for the heavily forested southern basins. The warm winter bias may be related to a too-low albedo for snow under tall vegetation, while the cool summer bias may indicate excess evaporation. In a comparison of the subbasins with the MAGS estimates, ERA-40 has more precipitation than the MAGS observations for the northern and western mountainous basins, but for those basins the data are sparse. For evaporation, ERA-40 has less variation across the basins than the MAGS estimate. ERA-40 appears to represent well the climatological gradient of deep soil temperature across the Mackenzie basin, from continuous permafrost in the north to no permafrost in the south.
\end{abstract}

\section{Introduction}

An important objective of the Global Energy and Water Cycle Experiment (GEWEX) is to improve our ability to simulate both water and energy exchange processes in global climate and weather models. The Mackenzie GEWEX Study (MAGS: Stewart et al. 1998; Stewart 2002; Rouse et al. 2003) was designed to address some of the high-latitude issues, where snow and ice play an important role in the surface energy ex-

Corresponding author address: Alan K. Betts, Atmospheric Research, 58 Hendee Lane, Pittsford, VT 05763.

E-mail: akbetts@aol.com changes. In an earlier paper (Betts and Viterbo 2000), we discussed the hydrological budgets and surface energy balance for subbasins of the Mackenzie River, using data from $2 \mathrm{yr}$ of the operational model of the European Centre for Medium-Range Weather Forecasts (ECMWF). This paper continues this work, with data from the ECMWF 40-yr reanalysis (ERA-40), which actually covers the $44 \mathrm{yr}$ of 1968-2001. ERA-40 was run in several parallel streams (Simmons and Gibson 2000). The analysis system uses a recent version of the model physics, including the land surface scheme described in Van den Hurk et al. (2000), and a 3D variational assimilation system. The horizontal resolution of the spectral model is triangular truncation at $\mathrm{T}_{\mathrm{L}}-159$, 


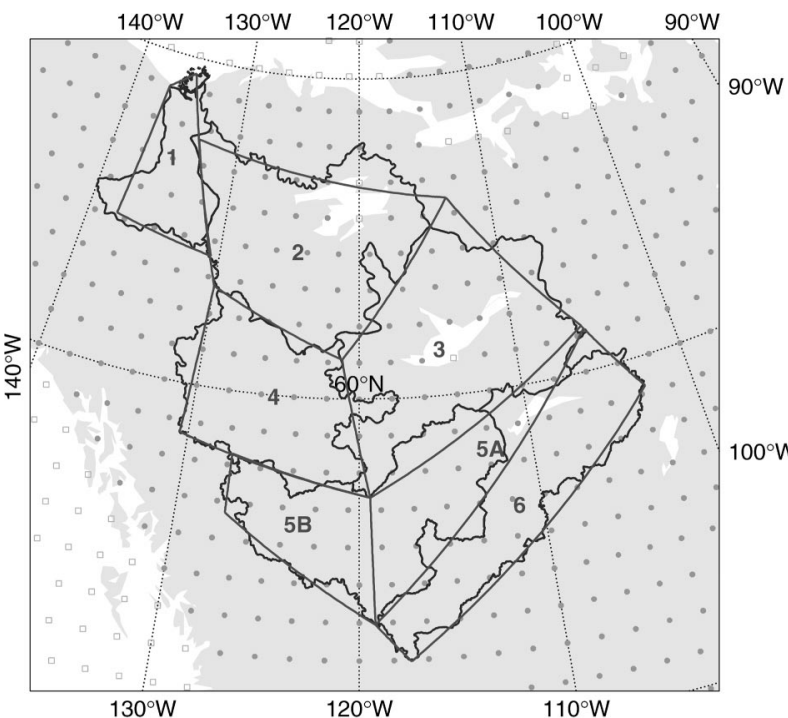

FIG. 1. River basin budgets in ERA-40 for the Mackenzie.

and there are 60 levels in the vertical, including a wellresolved boundary layer and stratosphere. [Documentation of the Integrated Forecast System (IFS), cycle $23 \mathrm{r} 4$, and a summary and discussion of the observations available at different times during the 40-yr reanalysis can be found online at http://www.ecmwf.int/research/ era/.] Surface energy and water budgets, and near- and subsurface variables averaged over river basins, are computed and archived during the analysis cycle at an hourly timescale. In this paper, using monthly means and datasets derived from MAGS observations, we assess the systematic biases in temperature and the surface energy and water budgets of ERA-40. Another paper addresses these biases for the Mississippi River basin (Betts et al. 2003). Walsh et al. (1998) compared observational estimates of Arctic precipitation and evaporation with 24 climate model simulations, and found that these climate models overestimated high-latitude precipitation.

MAGS has yielded several important observational studies. Stewart et al. (2000), Rouse (2000a), and Rouse et al. (2003) discuss the broad seasonal and regional character of the energy and water budgets of the Mackenzie, observational studies of the snow and lake hydrology, and developments in modeling. More detailed analyses of shallow lakes and northern wetlands, underlain by ice-rich permafrost, are presented in Rouse (2000b). In a special issue on MAGS the difficulty of closing the atmospheric moisture budget using rawinsonde data, and reconciling it with the surface water budget, is outlined by Strong et al. (2002). In the same special issue, several papers (Louie et al. 2002; Cao et al. 2002) analyze in detail the unusual 1994/95 water year, in which the 1995 spring melt was the earliest on record (Marsh et al. 2002).

\section{River basin intercomparisons}

For ERA-40, averages over selected basins are output for hourly time intervals (accumulated from the full time resolution data) for selected river basins. We averaged the hourly data up to 1 month, as discussed below. The representation of the Mackenzie River basins in ERA40 is shown in Fig. 1. The ERA-40 averages are over all grid points, indicated as dots over land, inside each polygon, which are approximations to the actual river basin boundaries shown. The Peel River is basin 1 (and it includes the Mackenzie delta); 2 is the Great Bear Lake basin; 3 is that of the Great Slave Lake; 4 is the Liard River basin; 5 is the Peace River basin, which is represented by two quadrilaterals, $5 \mathrm{~A}$ and $5 \mathrm{~B}$ (with $5 \mathrm{~A}$ being a rather poor fit to the eastern part); and 6 is the Athabasca River basin. All of our results will be presented as these area averages. Table 1 lists the basin drainage areas, their approximation in the ECMWF model, and their mean elevation, as well as the standard deviation (std dev); maximum, and minimum heights, all calculated on the model grid.

\section{a. Monthly averages from short-term forecasts}

The model analysis cycle uses 6 - $h$ forecasts from analyses at 0000, 0600, 1200, and 1800 UTC. From the 0000 and 1200 UTC analyses, forecasts were extended to $36 \mathrm{~h}$. Three monthly averages were constructed from

TABLE 1. Mackenzie subbasin drainage areas and their model representation.

\begin{tabular}{|c|c|c|c|c|c|c|}
\hline \multirow[b]{2}{*}{ Subbasin } & \multirow{2}{*}{$\begin{array}{l}\text { Drainage area } \\
\qquad\left(\mathrm{km}^{2}\right)\end{array}$} & \multirow{2}{*}{$\begin{array}{l}\text { ERA-40 area } \\
\qquad\left(\mathrm{km}^{2}\right)\end{array}$} & \multicolumn{4}{|c|}{ Model elevation (m) } \\
\hline & & & Mean & Std dev & Max & Min \\
\hline 1: Peel River & 117127 & 108187 & 686 & 384 & 1284 & 121 \\
\hline 2: Great Bear Lake & 421191 & 367573 & 478 & 361 & 1506 & 187 \\
\hline 3: Great Slave Lake & 378245 & 418757 & 348 & 99 & 565 & 196 \\
\hline 4: Liard River & 273395 & 283920 & 991 & 315 & 1515 & 412 \\
\hline 5: Peace River & 319110 & 344659 & & & & \\
\hline $5 \mathrm{~A}$ (east) & & (206 549) & 573 & 198 & 1122 & 286 \\
\hline 5B (west) & & (138 110) & 1147 & 213 & 1482 & 782 \\
\hline 6: Lake Athabasca & 285111 & 260982 & 651 & 333 & 1611 & 358 \\
\hline Total & 1791857 & 1784078 & & & & \\
\hline
\end{tabular}


TABLE 2. Distribution of vegetation across the Mackenzie in ERA-40 as percent of basin.

\begin{tabular}{lrrrrrrr}
\hline \multicolumn{1}{c}{ Basin } & 1 & 2 & 3 & 4 & $5 \mathrm{~A}$ & $5 \mathrm{~B}$ & 6 \\
\hline High vegetation & 44 & 56 & 64 & 77 & 90 & 92 & 91 \\
Evergreen needleleaf (3) & & & 26 & 13 & 25 & 49 & 69 \\
Deciduous broadleaf (5) & 43 & 17 & 32 & 51 & 55 & 43 & \\
Interrupted forest (19) & 1 & 39 & 5 & 12 & 10 & & 21 \\
Low vegetation & 56 & 40 & 33 & 23 & 10 & 7 & 9 \\
Tundra (9) & 53 & 15 & 10 & 23 & & 5 & 1 \\
Bogs/marsh (13) & 3 & 25 & 6 & & 2 & & 1 \\
Deciduous shrubs (17) & & & 17 & & 1 & & 4 \\
Crops/mixed farming (1) & & & & & 7 & 2 & 3 \\
Water & 4 & 3 & & & & \\
\hline
\end{tabular}

twice-daily segments of the 0-12-, 12-24-, 24-36-h forecasts, verifying at the same time. They will be identified by the notation $0-12-\mathrm{h} \mathrm{FX}$, etc. We shall use these to look at the spinup of the model fields and fluxes (specifically precipitation) in the first $36 \mathrm{~h}$. We also constructed monthly averages from the four 6-hourly segments of the analysis cycle, which we shall use to discuss the closure of the water budget in the model, which includes the modification of soil moisture and snow depth in the analysis cycle. For a few years (1958, 1973, 1989-94), which were at the beginning of the ERA-40 analysis streams, basin averages of the 0600 and 1800 UTC 6-h forecasts were not archived, so these years are excluded from the analysis of water budget closure. Fortunately, combining the two 0-12-h forecasts from 0000 and 1200 UTC gives almost the same daily precipitation fluxes as combining the four $0-6-\mathrm{h}$ forecasts.

\section{b. Distribution of vegetation in ERA-40}

The land surface scheme in ERA-40 has separate tiles for high- (that is forests) and low-vegetation classes that are treated differently (Van den Hurk et al. 2000). At high latitudes the primary difference is that there is a tile for "high vegetation with snow beneath," which has a distinct energy budget for the snow layer, that is only partly coupled to the boundary layer. In addition, snow beneath forests has a much lower albedo (15\%) to represent the shading effect of the canopy, than snow lying on top of low vegetation (whether tundra, marsh, or cropland). The model does not represent snow on the tree canopy, nor does it have a model for the horizontal redistribution of snow on the subgrid scale. Earlier land surface schemes in the ECMWF model had too high an albedo for the boreal forests in winter (Viterbo and Betts 1999), and after this was corrected there was too much evaporation of snow in winter (Betts et al. 1998, 2001b).

In ERA-40, each grid square now has a fraction and type of both high and low vegetation. The distribution across the Mackenzie basin of these is shown in Table 2. There is a transition from low vegetation (primarily tundra) being dominant in the north to more than $90 \%$ forest in the south. Basins 2 and 3 (Great Bear and Great

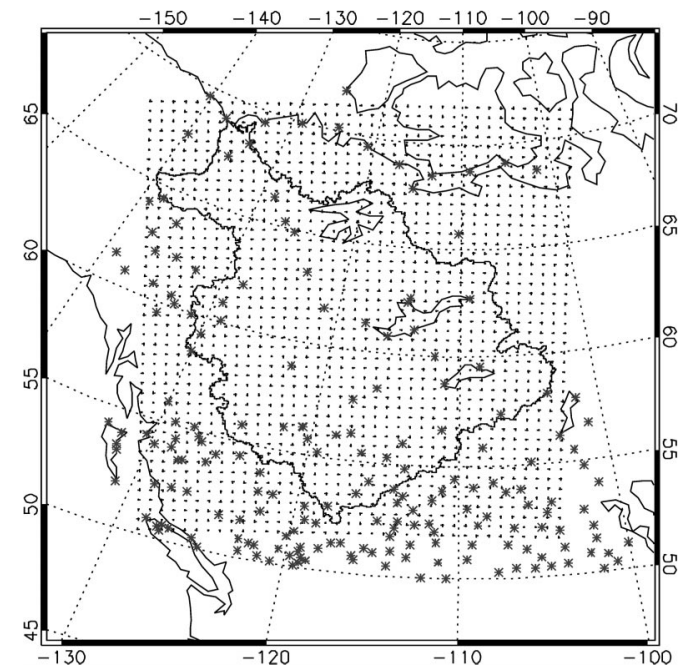

FIG. 2. Long-term ( $>25 \mathrm{yr}$ record) climate stations in or near the Mackenzie basin (from Louie et al. 2002).

Slave Lakes) have a small percent of water, in fact each has a single "lake point" at the T-159 resolution of ERA-40, but the impact of these on our analysis is small.

\section{c. Available surface observations}

The observations available to validate the model are limited, because data are sparse in the Mackenzie basin. MAGS has produced three basin-averaged monthly products. Precipitation and temperature from 1950-97 were produced by Louie et al. (2002). Climate station density is quite sparse in the Mackenzie basin, as shown in Fig. 2. Of the 194 stations shown (with records $>25$ yr), only 46 lie within or on the Mackenzie River basin boundary. There are more stations in the south in the Lake Athabasca and Peace River basins, a few in the Liard River basin, and around Great Slave Lake, but only one within the Peel River basin, and a few on the perimeter. Monthly mean fields cannot be generated directly from station data. Precipitation data were first corrected for all known measurement errors, including corrections for gauge undercatch (Mekis and Hogg 1999; Metcalfe et al. 1997). A first-guess field of 30yr normal temperature and precipitation (Seglenieks and Soulis 2000) was constructed on the $0.5^{\circ}$ grid shown in Fig. 2. Monthly deviations of station data from the station normals were optimally interpolated to this grid (for precipitation, the deviations were first further normalized by the normal precipitation). Monthly mean maps of temperature and precipitation were then produced (Louie et al. 2002) by combining the normal and departures grids, and these were averaged over the six Mackenzie subbasin drainages in Table 1, and the Mackenzie River as a whole.

An estimate of evaporation from 1953-96 was produced for MAGS on the same grid by Louie et al. (2002), based on the method of Morton (1983), who 
TABLE 3. Streamflow gauges used for basin estimations.

\begin{tabular}{|c|c|c|c|}
\hline Gauge & Location & $\begin{array}{c}\text { Drainage } \\
\left(\mathrm{km}^{2}\right)\end{array}$ & Basin estimation \\
\hline 10LC014 Mackenzie River at Arctic Red River (1972-2000) & $67^{\circ} 27^{\prime} 30^{\prime \prime} \mathrm{N}, 133^{\circ} 44^{\prime} 41^{\prime \prime} \mathrm{W}$ & 1680000 & Mackenzie, Sum of $2,3,4,5,6,7$ \\
\hline 10MC002 Peel River above Fort McPherson & $67^{\circ} 14^{\prime} 56^{\prime \prime} \mathrm{N}, 134^{\circ} 52^{\prime} 59^{\prime \prime} \mathrm{W}$ & 70600 & Mackenzie and 1 \\
\hline 10LA002 Arctic Red River near the mouth & $66^{\circ} 47^{\prime} 24^{\prime \prime} \mathrm{N}, 133^{\circ} 04^{\prime} 54^{\prime \prime} \mathrm{W}$ & 18600 & Mackenzie and 1 \\
\hline 10GC001 Mackenzie River at Fort Simpson & $61^{\circ} 52^{\prime} 07^{\prime \prime} \mathrm{N}, 121^{\circ} 21^{\prime} 25^{\prime \prime} \mathrm{W}$ & 1270000 & Sum of $3,4,5,6,7$ \\
\hline 10ED002 Liard River near the mouth (1972-2000) & $61^{\circ} 44^{\prime} 34^{\prime \prime} \mathrm{N}, 121^{\circ} 13^{\prime} 40^{\prime \prime} \mathrm{W}$ & 2275000 & 4 \\
\hline 07KC001 Peace River at Peace Point (1959-2000) & $59^{\circ} 06^{\prime} 50^{\prime \prime} \mathrm{N}, 112^{\circ} 25^{\prime} 35^{\prime \prime} \mathrm{W}$ & 293000 & Sum of $5 \mathrm{~A}, 5 \mathrm{~B}$ \\
\hline 07HA001 Peace River at Peace River (1959-2000) & $56^{\circ} 14^{\prime} 41^{\prime \prime} \mathrm{N}, 117^{\circ} 18^{\prime} 46^{\prime \prime} \mathrm{W}$ & 186000 & $5 \mathrm{~B}$ \\
\hline 07DA001 Athabasca River below McMurray & $56^{\circ} 46^{\prime} 50^{\prime \prime} \mathrm{N}, 111^{\circ} 24^{\prime} 00^{\prime \prime} \mathrm{W}$ & 133000 & 6 \\
\hline
\end{tabular}

gave an evaluation of the method based on the water budget of 143 river basins. Morton's model is a semiempirical method, which uses the air temperature, dewpoint, percentage of possible sunshine, latitude, elevation, and precipitation. Monthly averages were produced for the Mackenzie River and the subbasins.

We also have monthly streamflow data (HYDAT 2000), with a range of record lengths, some back to 1958, which we have used to estimate the annual streamflow for most of our subbasins, and the monthly streamflow for the Mackenzie River as a whole. For comparison with model runoff, we converted all streamflow estimates to millimeters by dividing by the area drained by a given gauge. Table 3 lists the gauges with their location and drainage area, for which basin comparisons they were used. We estimated the monthly streamflow (converted to millimeters per month) for the Mackenzie River near its mouth by summing the first three in Table 3. We made estimates for the subbasins also (except basin 3: Great Slave Lake), but we shall present here the comparison for the Mackenzie as a whole. We have no estimates of basin storage, and ERA-40 has no routing model, so comparisons of streamflow and model runoff can provide only limited information on the water budget.

\section{44-yr overview}

The idea of renanalysis is to use one recent "frozen" model and data assimilation system to cover the entire period, in contrast to operational analyses in which the modeling system is revised on a frequent basis, as improved numerical or data assimilation schemes and physical parameterizations are introduced, along with increases in resolution. However, although the model is frozen, the data going into the reanalysis has changed markedly in the $44 \mathrm{yr}$ from 1958 to 2001, and this has a major impact on the analyses. There are three important epochs in ERA-40: 1958-72, before "satellite data," when the upper-air analysis depends on the sounding data; 1973-86, starting with the assimilation of the radiances from the first satellite infrared channels on the vertical temperature profiler radiometer (VTPR) and, from late 1978, infrared and microwave sounders from the Television and Infrared Observational Satellite (TIROS) Operational Vertical Sounder (TOVS) suite of instruments; and 1987-2001, with the addition of information of radiances from the satellite microwave channels of the Special Sensor Microwave Imager $(\mathrm{SSM} / \mathrm{I})$ to the atmospheric water vapor assimilation over the ocean.

As satellites are replaced, they are compared during their overlap period, and bias corrections are introduced for each satellite. However, these corrections do not remove all the inhomogeneities in the record. In addition, aerosols from volcanic eruptions, such as Mount Pinatubo in 1991/92, affect the infrared emission, and have not been properly accounted for in ERA-40 (P. Kållberg 2002, personal communication). There are also many changes in the conventional data, and over the Mackenzie, in particular, there are less data in the 1960 's. In the next section, we show how the spinup of the model precipitation has changed markedly with time, and how it depends on the atmospheric moisture analysis. In general, the fit to precipitation observations has improved with time.

\section{a. Model precipitation spinup and bias}

\section{1) Change of SPINUP AND BIAS WiTH TIME}

The model hydrological cycle is not in balance during the 6-h analysis cycle. Precipitation generally increases in ERA-40 in mid- and high latitudes during the first $36 \mathrm{~h}$ of forecasts. This spinup of precipitation varies considerably over the period of the reanalysis. The upper panel in Fig. 3 shows, on the left-hand scale, the annual precipitation from the MAGS data and the annual ERA40 precipitation from the $0-12-\mathrm{h}$ FX. On the right is the column soil moisture (CSM) in the model. We see that the model has a negative bias of precipitation compared to the observations in the early 1960s, and CSM is correspondingly low; while in the middle 1970s, the model has a positive bias in precipitation and, correspondingly, the highest mean soil moisture. The lower panel plots, on the left-hand scale, the spinup of model precipitation from the 0-12- to the 24-36-h FX, and its components: convective precipitation (CP), and largescale precipitation (LSP), which is the dominant term. The right-hand scale shows the bias of the 0-12-h FX precipitation from the MAGS observations (the scale is both different and inverted). The trend of the bias mir- 

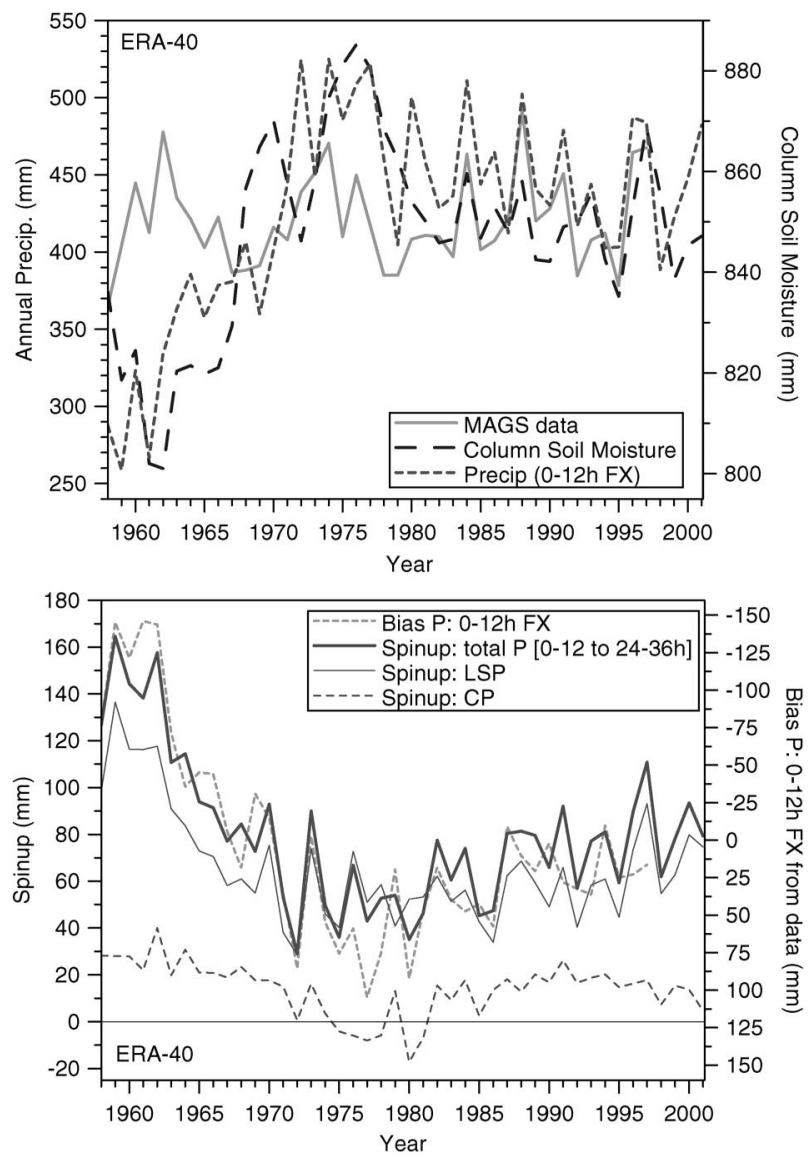

FIG. 3. (top) Annual mean precipitation in model and MAGS observations and column soil moisture; (bottom) model precipitation spinup and bias from observations.

rors quite closely the model spinup on an annual basis from large negative bias at the beginning of ERA-40, coupled with a large spinup, to a positive bias in the mid-1970s with the smallest spinup, to, finally, the smallest bias in the 1990s with an intermediate spinup of precipitation.

This change of bias and spinup with time appears to be linked to changes in the analysis increment of water vapor during the 44 yr. Figure 4 (upper panel) shows the annual mean atmospheric total column water vapor (TCWV) and the analysis increment of TCWV. The increment, on the right-hand scale, shows a drift with time from a negative value at the start of the reanalysis, to near zero or positive in the mid-1970s, to again negative in the 1990s. The TCWV in the analysis has a significant upward drift in the 1960s, which we believe is spurious. The middle and lower panels show that both the bias of the model 0-12-h FX precipitation from the MAGS observations, and the spinup of model precipitation are correlated with the TCWV analysis increment. The analysis removes TCWV, which reduces precipitation in the analysis cycle, and the model then spins up to restore precipitation. For the period 1974-81, when the analysis
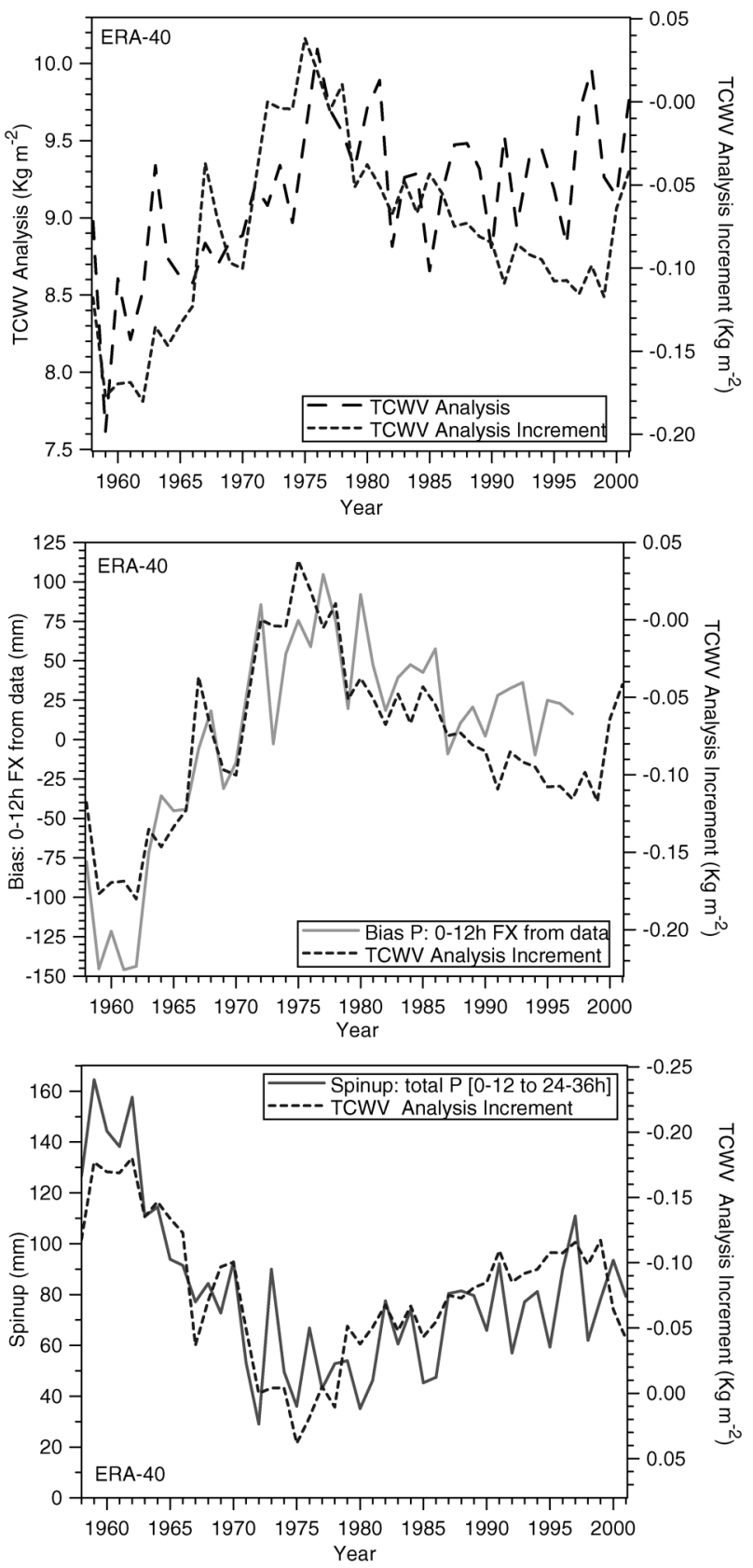

FIG. 4. (top) Annual variation of TCWV and its analysis increment, (middle) model precipitation bias, and (bottom) model precipitation spinup.

increment is near zero, the spinup is a minimum. For the same period, the mean bias is $+66 \mathrm{~mm}, 16 \%$ of the MAGS precipitation, and within the probable error of the observations. Because precipitation is the primary driver of the hydrological cycle, this spinup variation over the $44 \mathrm{yr}$ of ERA-40 is of fundamental importance, and it is being investigated further. Initially, we thought that the different epochs of satellite data were the primary driver. However, the large ramp of spinup, bias, and TCWV analysis increment seen in the 1960s appears 
complete by 1972 , just before the incorporation of the VTPR satellite data, so changes or errors in the conventional data (or its use) must be responsible for this shift. One source of error, which had a large impact over the North American continent, has been identified. The atmospheric humidity in one of the datasets used for the period 1958-63 had a dry bias, up to several grams per kilogram in summer, due to an unit conversion problem.

The annual cycle in TCWV is also seen in the precipitation spinup. Figure 5 (upper panel) shows the monthly variation of spinup and the TCWV analysis increment during the early part of the analysis. The lower panel shows the correlation between monthly mean spinup and TCWV analysis increment for the whole of ERA-40. Two regression lines are shownone through the origin.

\section{2) ANNUAL CYCLE OF PRECIPITATION SPINUP AND BIAS}

We will now present data from three periods-195870, 1974-81, and 1987-97-to illustrate differences in the mean annual cycle. Figure 6 shows the mean annual cycle for the three periods of the observed Mackenzie precipitation (upper panel), the model precipitation spinup between the 0-12- and 24-36-h FX (middle), and the TCWV analysis increment (lower). The Mackenzie precipitation remains low in spring until May and peaks sharply in July. There is little difference in the mean between the periods. The model spinup shows a marked difference between the periods. Spinup is larger in winter in the 1960s. The first and last periods have a July spinup maximum (as does precipitation), while in the middle period, the spinup is low and has a dip in summer, related to a spindown in convective precipitation (not shown, although it can be seen in the annual average in Fig. 3 during this period). The annual cycle of the TCWV increment bears some resemblance to the spinup, but the peak is shifted to June. The reason for this is probably that the model has a distinct seasonal bias in precipitation, shown in Fig. 7. The upper panel shows the bias of ERA-40 precipitation in the 0-12-h FX. It shows not only the marked difference between the three periods (seen in Figs. 3 and 4), but it also shows that the bias has a spring peak and a fall minimum. In the 24-36-h FX (lower panel), the difference in bias between the periods has reduced, and it is clear that the model has a high precipitation bias in MayJune, and a low bias in August-September. The cause of this is still under investigation.

\section{3) Precipitation SPINUP AND BIAS FOR THREE PERIODS}

The left-hand panels of Fig. 8 plot monthly precipitation, derived from twice-daily 12-24- and 24-36-h forecasts against the corresponding model precipitation derived from twice-daily $0-12-\mathrm{h}$ forecasts. Three time
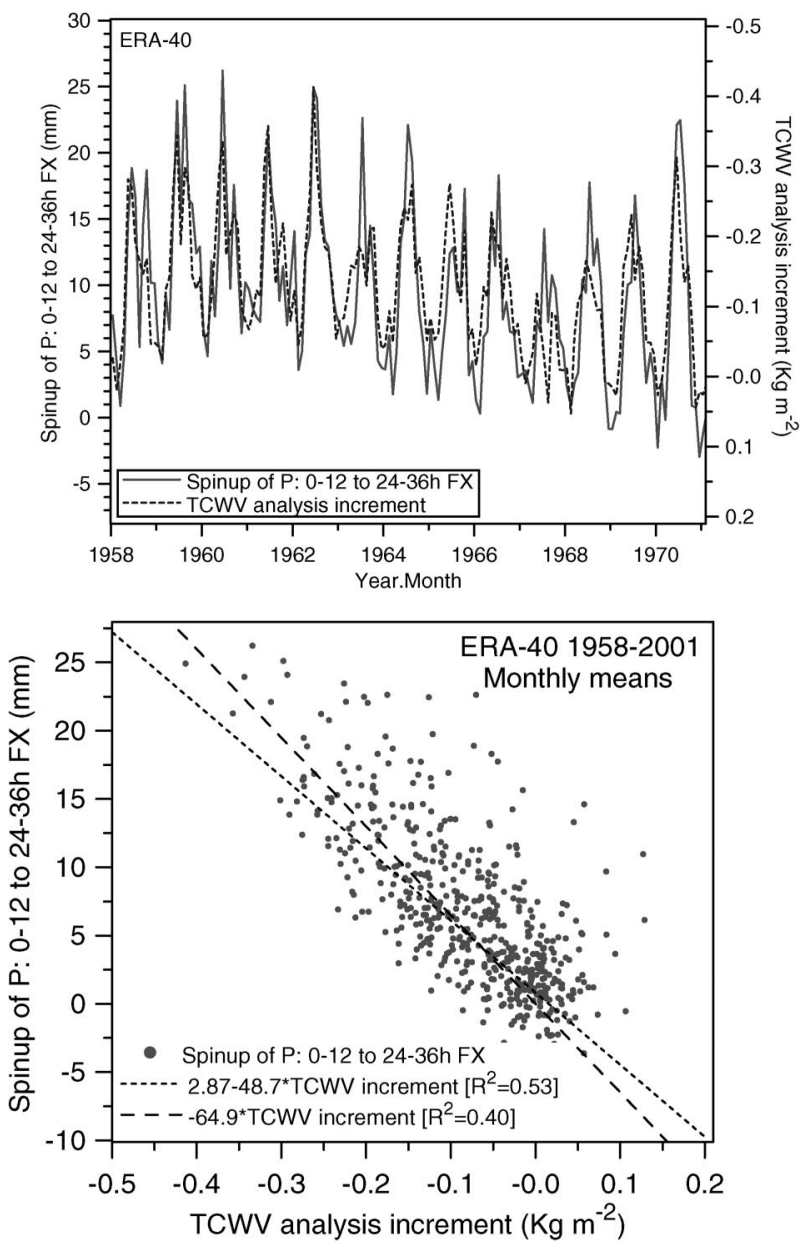

FIG. 5. (top) Monthly time series of model spinup and TCWV increment and (bottom) scatterplot of spinup against TCWV increment.

periods are shown. The upper-left panel is for the early period, where we see model precipitation increases out to the 24-36-h FX. The slope of the linear regression lines through the origin are shown, together with their $R^{2}$ coefficients. Precipitation in the $24-36-\mathrm{h}$ FX is $32 \%$ greater than in the $0-12-\mathrm{h}$ FX. The middle-left panel for 1974-81, shows a spinup of only $9 \%$, and this is complete by the 12-24-h FX. The lower-left panel shows the more recent period, showing the precipitation spinup increasing from $15 \%$ to $19 \%$ with forecast time.

\section{4) COMPARISON OF ERA-40 PRECIPITATION AND MAGS PRECIPITATION}

The panels on the right-hand side of Fig. 8 plot monthly ERA-40 precipitation against the MAGS basin average observations, together with the linear regression lines. The upper-right panel for the early period shows that the $0-12-\mathrm{h}$ FX precipitation is much lower than the observations, but by the 24-36 h, FX becomes comparable, with considerable scatter. For 1974-81 (middle 

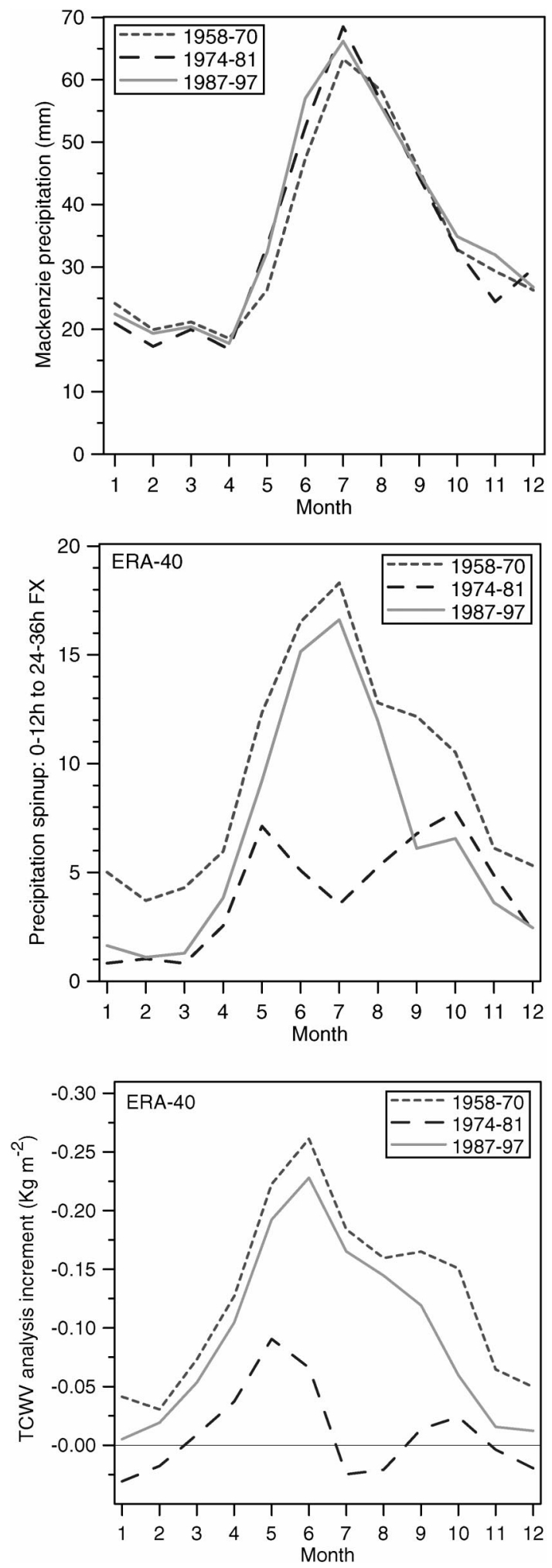

FIG. 6. Mean annual cycle of observed Mackenzie precipitation, model precipitation spinup, and TCWV analysis increment for three periods.
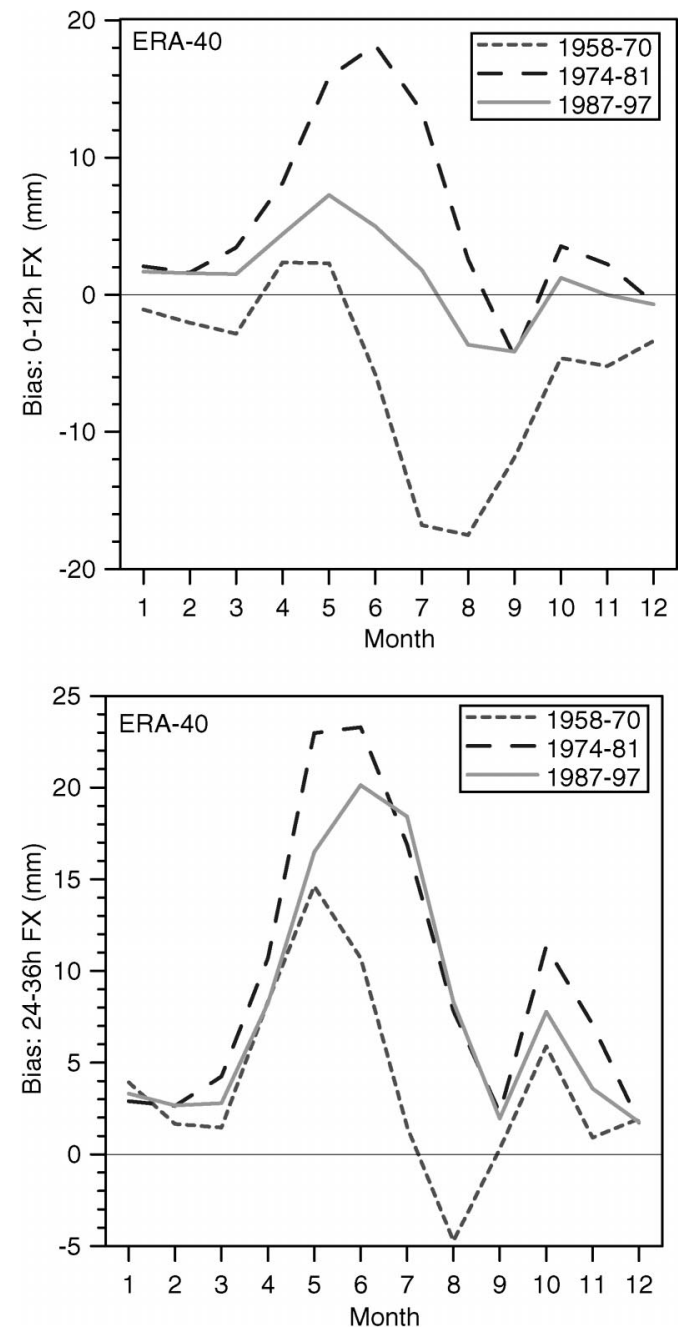

FIG. 7. Mean annual cycle of 0-12- and 24-36-h FX bias for three periods.

right), the model precipitation is greater than the observations by $15 \%$ for the $0-12-\mathrm{h} \mathrm{FX}$ and $25 \%$ for the 12-24-h FX. The lower-right panel for 1987-97 (when the MAGS precipitation time series ends) shows slightly smaller high bias increasing from $2 \%$ to $18 \%$ with the model spinup. Note that the $R^{2}$ correlation coefficient increases systematically with time, reaching 0.91 for the last decade for which we have these monthly averages for the Mackenzie basin, suggesting both that the analysis is improving, and that ERA-40 is representing the variability of precipitation rather well on the monthly timescale.

The MAGS precipitation data have been corrected for known errors and biases (Metcalfe et al. 1997; Mekis and Hogg 1999, Louie et al. 2002). The slopes of the regression lines in the figures are of course dominated by the summer data, when monthly precipitation is highest. We can conclude that the ERA-40 precipitation is best in the last decade in the representation of the monthto-month variability, when both infrared and microwave 

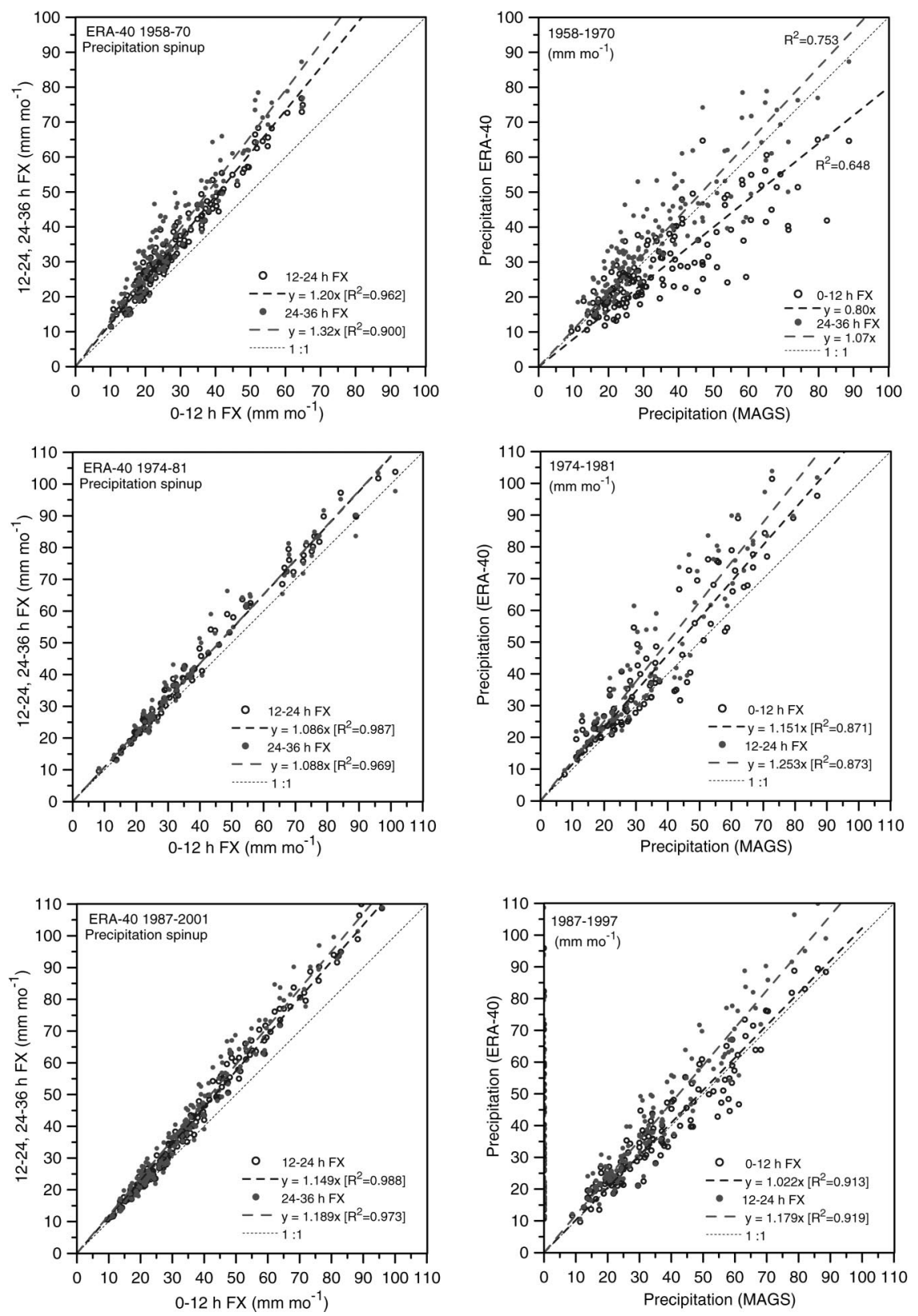

FIG. 8. (left) Spinup of ERA-40 precipitation for three epochs, and (right) comparison of ERA-40 with MAGS precipitation estimates.

satellite radiances are available for the analysis. In terms of bias the issue is less clear, because of the substantial changes in both bias and spinup with time shown in Figs. 3-7, and the fact that the MAGS precipitation data may not be unbiased, despite the correction procedures. The seasonal cycle of the model precipitation bias shown in Fig. 7 (high in spring and low in fall) is, however, probably real. In the most recent period, the bias of the 0-12-h FX precipitation is small, while after spinup, it is likely that ERA-40 has a small, high bias for the Mackenzie. We shall look at the individual basins in more detail in section 4.

\section{b. Comparison of ERA-40 evaporation with MAGS estimate}

Figure 9 shows the annual cycle of the MAGS estimate (Louie et al. 2002) of basin evapotranspiration (ET) for the three periods, and the bias of the ERA-40 0-12-h FX total evaporation from the MAGS estimate (lower curves). Standard deviations are shown for the recent period. In winter, the MAGS estimate (itself based on a model, but using station observations) gives a very small downward transport of vapor to the cold surface, while ERA-40 is generally slightly positive 


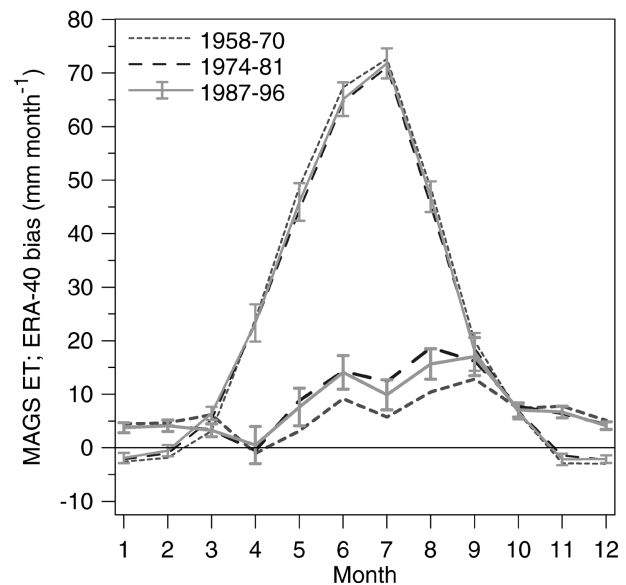

FIG. 9. MAGS ET estimate and ERA-40 bias from MAGS estimate.

with about $5 \mathrm{~mm}$ month ${ }^{-1}$ more evaporation than the MAGS estimate. This bias decreases to near zero in

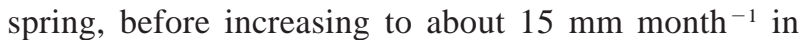
summer, with a peak in August-September. Annual evapotranspiration from ERA-40 is higher than a MAGS estimate by $30 \%$. In the summers from 1958-70, when the ERA-40 precipitation is low, the evaporation bias is also lower. In a later section, we shall conclude from the water balance of the Mackenzie River, that the ERA40 evaporation is probably biased high (see Table 4 later).

\section{c. Comparison of Mackenzie streamflow and ERA-40 runoff}

We have streamflow data for the Mackenzie River from 1973 to the present. Figure 10 (upper panel) compares the mean annual cycle (1973-2000) of streamflow for the Mackenzie and the corresponding runoff in ERA40. The two differ considerably: streamflow at the mouth of the Mackenzie remains very low until May and peaks in June. In contrast, the model runoff peaks earlier in April (when snow melts in the model), and there is a second, smaller peak in August. Louie et al. (2002) suggest that the average drainage time for the basin is of the order of 2 months.

The two runoff peaks in ERA-40 are discussed in Van den Hurk et al. (2000). The first model peak occurs when snowmelt runs off "instantaneously" over the frozen ground. In addition to not having river routing, the model does not represent the freeze-thaw cycles as water penetrates the snowpack and ground and refreezes, which in nature also delay spring runoff. Once the ground thaws, including the deepest soil layer, water can drain through the soil, and above a threshold of liquid water content in the 100-289-cm soil layer, deep drainage increases rapidly. This accounts for the second peak in August in the model.

The lower panel compares total annual streamflow on
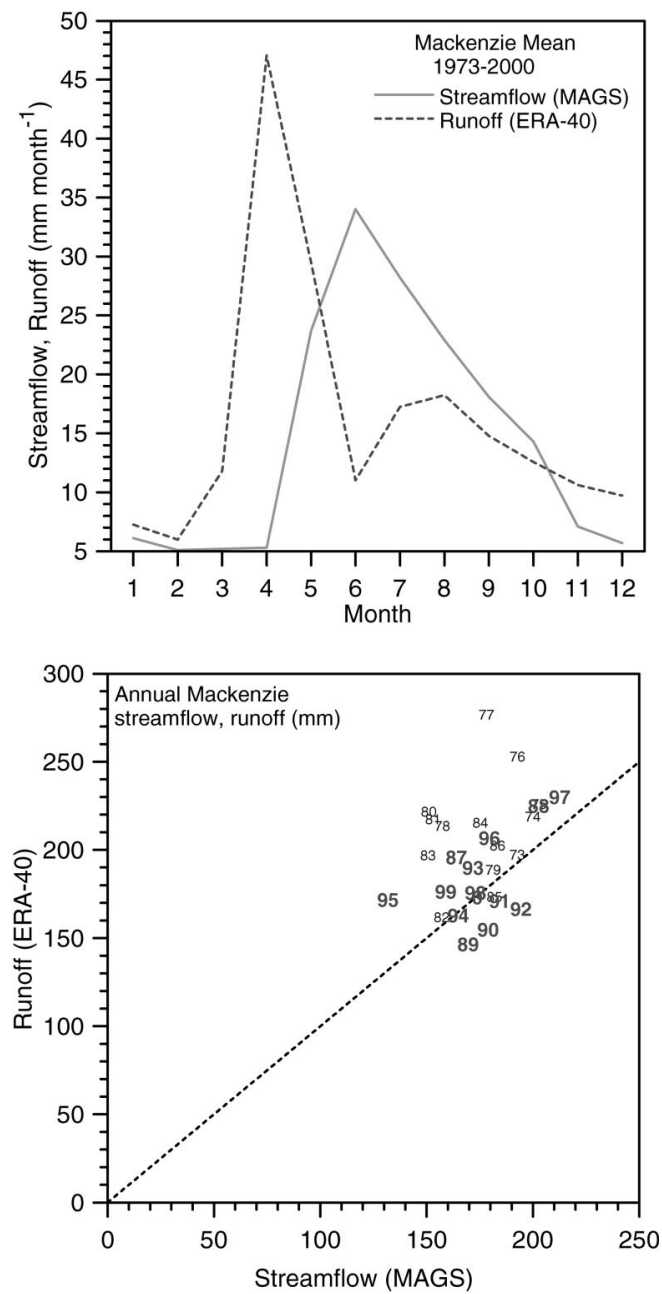

FIG. 10. Comparison of Mackezie streamflow and ERA-40 runoff: (top) annual cycle and (bottom) annual total.

the Mackenzie River and model runoff. The numbers correspond to the year, and we have distinguished the period before 1986, when precipitation was higher, from the more recent period from 1987 onward (larger numerals). Runoff is generally higher in the earlier period, as would be expected from the greater precipitation. In the more recent period, the model runoff and the observed streamflow are comparable, but the interannual variability is not well correlated. One additional complication is that there was an error in the snow analysis initially in ERA-40, which reduced the snow water equivalent (SWE) of observations introduced in the analysis by a factor of about 0.25 . This error was not corrected until the two analysis streams had reached January 1974 and November 1994 (P. Kållberg 2002, personal communication), so it is likely that snowmelt is reduced for the years 1973 (and partially for 1974), and 1990-94. We see that annual runoff is generally lower in these years. Given this error, and the absence of river routing in ERA-40, which plays a major role 

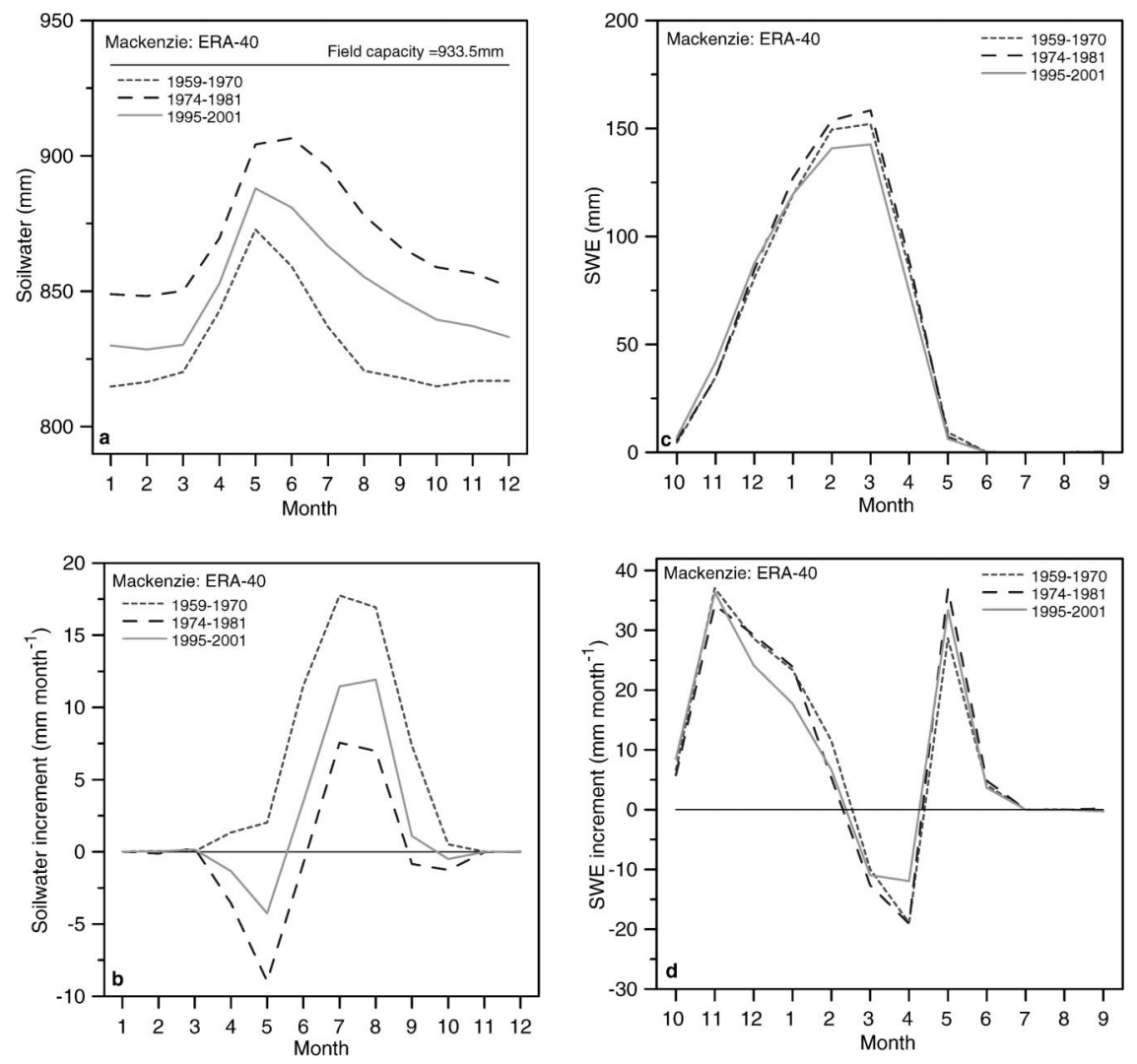

FIG. 11. (a) Mean annual cycle of column soil water, (b) soil water analysis increment, (c) total snow water equivalent, and (d) SWE analysis increment for three data periods.

on the Mackenzie with its large lakes and long residence time before precipitation falling in the south reaches the mouth, we cannot draw many conclusions about this aspect of the hydrological cycle. The annual runoff in ERA-40 is broadly consistent with, but a little higher than, the annual streamflow, and probably snowmelt is too early in the model.

\section{d. Surface water reservoirs and analysis increments}

In this section, we analyze the surface water reservoirs and their analysis increments. Averages for three periods are shown for 1959-70, 1974-81, and 19952001.

\section{1) SoIL WATER}

The ERA-40 soil water analysis modifies soil water in the first three soil layers $(0-7,7-28$, and $28-100 \mathrm{~cm})$, subject to certain constraints, based on analysis increments of 2-m temperature and humidity (Douville et al. 2000).

Figure 11 shows for the three analysis periods the mean annual cycle of column (0-2.89 m depth) soil water (Fig. 11a), and the corresponding soil water analysis increments (Fig. 11b). The early period, 1959-70, when precipitation has a large spinup, has the lowest column soil water and the largest annual analysis increment (mean of $58 \mathrm{~mm}$ ). In the middle period (197481 ), when precipitation in the analysis cycle is largest compared to observations (Fig. 3), soil water is largest, and the analysis increment is negative in spring and fall and positive in summer with a near-zero annual mean $(-1 \mathrm{~mm})$. In the recent period, when $0-12-\mathrm{h}$ FX precipitation is closest to the MAGS observations, soil water has intermediate values, and the mean annual increment is $22 \mathrm{~mm}$, again with the main contribution in summer. The soil water analysis (Douville et al. 2000), which responds to analysis increments of 2-m temperature and humidity, is playing an important role in the liquid water budget. Soil water is being added in the warmer seasons, and excess soil water is being removed, for example, in the spring in the late 1970s, when precipitation is high. However, because there is evidence that summer evaporation is too high in the model (see Fig. 9 and Table 4, later), improvements in the soil water analysis may be possible.

\section{2) SNOW RESERVOIR}

ERA-40 has a single snow layer, with modeled SWE and snow depth, linked by a snow density, which is 
computed as a function of mean snow age (Van den Hurk et al. 2000). Snow density evolves exponentially from a minimum density for new snow of $100 \mathrm{~kg} \mathrm{~m}^{-3}$ to an aged maximum value of $300 \mathrm{~kg} \mathrm{~m}^{-3}$ with an $e$ folding time of about 4 days, following the formulation of Douville et al. (1995). A snow depth analysis uses snow depth observations, in addition to a nudging toward climatology (with a 12-day timescale), because in many areas the snow observations are inadequate. Snow density is rarely measured, so the analysis uses the model snow density to convert between snow depth and SWE. Figures 11c and 11d show that the annual cycle of SWE in the model and the SWE analysis increments are rather insensitive in the mean to the time period. We have wrapped the time axis to show the year from October to September, to show the unbroken frozen winter period, although the actual data are for calendar years. The interannual variability of SWE is very small for the northern basins, reflecting the fact that the SWE is largely determined by a climatology, but varies considerably for the southern basins where there are snow observations (not shown).

The annual cycle of the SWE analysis increment is peculiar, with the addition of SWE from October to February and from May to June, and the removal in March and April. In these averages, the snow analysis adds about $109 \mathrm{~mm}$ of SWE annually, which is only a little smaller than the mean annual snowfall in the analysis cycle, clearly an undesirable feature. The large addition of SWE in May results from the too-early melt in the model in April (Fig. 10). Model snow depth is too small in May, when compared with the observations, and the analysis adds snow. Although this has an adverse impact on the model hydrology, it reduces the model warm temperature bias (see next section) in May (because there is still observed snow on the surface). The early melt in the model is still under investigation, but it may be related to a simplification in the snow thermal budget. The thermal budget of snow is represented by a single layer (unlike the soil which has four layers, including a shallow first layer of thickness $7 \mathrm{~cm}$ ). To give a reasonable surface diurnal cycle over deep snow and ice, snow depth was also limited to $7 \mathrm{~cm}$ in the calculation of thermal capacity of the snow layer. While this improves the surface diurnal cycle of temperature, it is likely that it increases the frequency when the snowpack reaches $0^{\circ} \mathrm{C}$ and melts. Snow that melts in the model is removed at once, whereas in nature it might refreeze deeper in the snowpack. Another factor that may be involved in the early snowmelt is that, for many basins, the model has a warm temperature bias in April (see Figs. 14 and 18, later).

The winter/early spring positive-negative pattern has probably a more complex origin, relating to the use of model snow density. In winter, except in the earliest epoch, there is no apparent underestimation of model precipitation in the analysis cycle (which might explain a small positive addition of SWE from the snow anal- ysis). However, the model compares snow depth with the observations, and this is critically dependent on the calculation of snow density by the model, which decays with an $e$-folding time of about 4 days to an aged maximum value of $300 \mathrm{~kg} \mathrm{~m}^{-3}$. If the observed snow does not age as fast as the model assumes (which is likely at the cold temperatures in winter of the Mackenzie basin, see next section), then the observed snow depths (of low density snow) are effectively interpreted by the analysis (using the higher model snow density) as higher SWE. This would give a spurious positive addition of SWE as long as the density of the observed snow is less than that calculated by the model (which tends to the asymptote of $300 \mathrm{~kg} \mathrm{~m}^{-3}$ ). The situation would reverse in March and April as temperatures rise and the observed snowpack ages (shrinking in depth) to a density similar to the model maximum, and the increments become negative to remove the excess snowpack in the model. In fact, it can be shown with a simple model of constant accumulation of snowfall (with no losses), that if the density of the observed snowpack rises in spring to become equal to that calculated by the model, then the winter positive increments and spring negative increments exactly cancel.

\section{e. Water budget closure}

This section summarizes the closure of the liquid and frozen water budgets in the ERA-40 analysis cycle. We have all components of the water budget for $36 \mathrm{yr}$ : 1959-72, 1974-88, and 1995-2001 (the missing years are those for which the basin averages were not archived for the 6-h forecasts from the 0600 and 1800 UTC analyses; see section $2 \mathrm{a}$ ).

\section{1) LIQUID AND FROZEN WATER BUDGET}

Figure 12 (upper panel) shows the terms in the 36yr mean annual cycle of the liquid water budget:

$$
\begin{aligned}
\Delta \mathrm{CSM}= & \text { Rain }+ \text { Melt }-E_{\text {liquid }}-\text { Runoff } \\
& +\mathrm{SM}_{\text {increment }} .
\end{aligned}
$$

The mean residual is tiny (not shown), less than about $0.5 \mathrm{~mm} \mathrm{month}{ }^{-1}$. The rainfall (heavy solid) peaks in summer, while the spring melt peaks in April. In this 36-yr mean, these terms are much larger than the soil moisture (SM) analysis increment, which also peaks in summer. Liquid evaporation is a large sink for moisture, again peaking in the summer months. The spring melt contributes to a peak in spring runoff over frozen ground, and to a recharge of the soil moisture reservoir $(\Delta \mathrm{CSM})$, which subsequently falls during the summer months.

The lower panel of Fig. 12 shows the terms in the corresponding frozen water budget: 

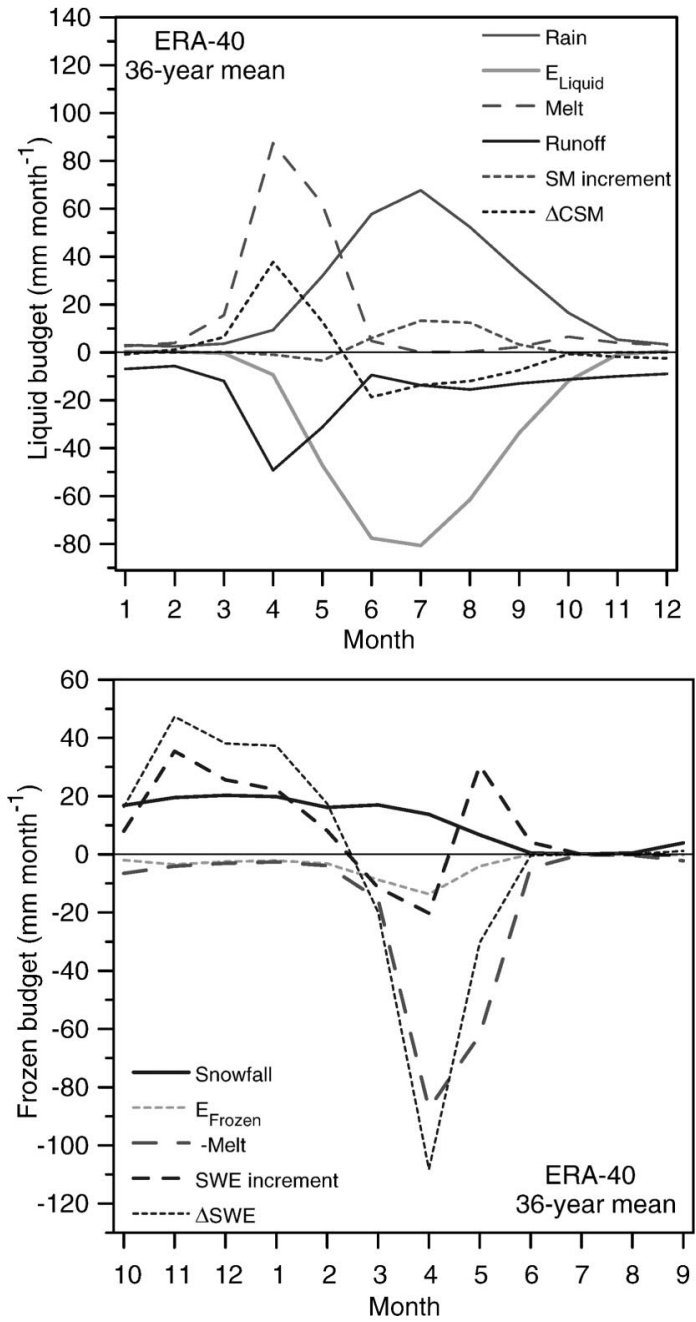

FIG. 12. Terms in the (top) liquid and (bottom) frozen water budget.

$$
\begin{aligned}
\Delta \mathrm{SWE}= & \text { Snowfall }-E_{\text {frozen }}-\text { Melt } \\
& +\mathrm{SWE}_{\text {increment }} .
\end{aligned}
$$

The residual (not shown) is again tiny, peaking at $1 \mathrm{~mm}$ month $^{-1}$ in April. We have, again, wrapped the time axis to show the year from October to September. Unlike the liquid budget, the SWE increment is comparable to the snowfall in size, and plays a major role in the budget, as discussed in the previous section. The frozen evaporation is a small term in comparison to the role of the melt in removing the snowpack in spring. This is a significant improvement in the frozen budget over an earlier cycle of the operational model (Betts and Viterbo 2000), in which snow evaporation was too large.

\section{2) Comparison with MAGS climatology}

Table 4 compares the ERA-40 mean annual water budget for the 24 calendar years-1971-72, 1974-88, and 1995-2001-with the Mackenzie climatology for
TABLE 4. Comparison of the ERA-40 water budget with the

\begin{tabular}{|c|c|c|c|c|}
\hline $\begin{array}{l}\text { Mean annual totals } \\
(\mathrm{mm})\end{array}$ & $\begin{array}{l}\text { ERA-40 } \\
\text { liquid }\end{array}$ & $\begin{array}{l}\text { ERA-40 } \\
\text { frozen }\end{array}$ & $\begin{array}{c}\text { ERA-40 } \\
\text { tot }\end{array}$ & $\begin{array}{l}\text { MAGS } \\
\text { climate }\end{array}$ \\
\hline Precipitation & 323 & 140 & 463 & 422 \\
\hline Evaporation & -327 & -38 & -366 & -274 \\
\hline Melt & 194 & -194 & & \\
\hline Runoff/streamflow & & & -207 & -176 \\
\hline Analysis increment & 17 & 97 & 114 & \\
\hline Climate residual & & & & -28 \\
\hline Storage change & 0 & -2 & -2 & \\
\hline
\end{tabular}
MAGS water budget climatology.

the 24 water years-from October 1972 to September 1996, from Louie et al. (2002). We compare the climatologies, because the MAGS budget ends in 1996, and our ERA-40 budget has missing components for 1973 and 1988-94. We see that the ERA-40 total water budget has $10 \%$ more precipitation and $18 \%$ more runoff (in this 24-yr mean 0-12-h FX) than the MAGS "climate," but has $34 \%$ more evaporation, and that the "extra" water comes from the analysis increments (mostly from the snow analysis). The MAGS water budget itself has a $-28-\mathrm{mm}$ residual $(-7 \%)$, suggesting perhaps that "observed" precipitation is underestimated, despite being corrected for undercatch. We conclude that it is likely that, while the 0-12-h FX ERA-40 precipitation may be realistic, the ERA-40 evaporation has a high bias.

\section{f. Temperature comparison}

Figure 13 compares the monthly mean $2-m$ temperature for the Mackenzie basin from ERA-40 and the MAGS observations. The 2-m temperature in the model is calculated by fitting a Monin-Obukhov profile be-

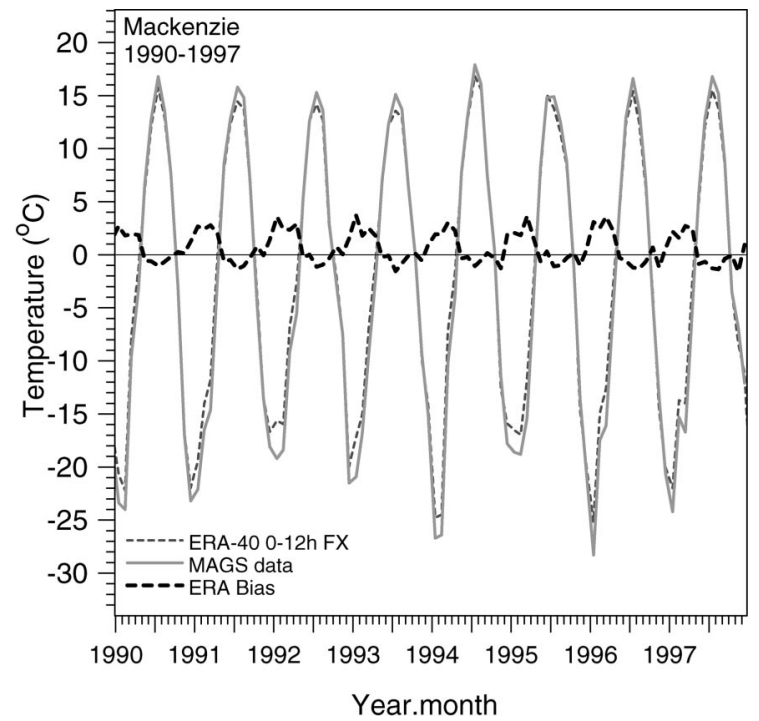

FIG. 13. Comparison of temperature for the Mackenzie basin with ERA-40. 


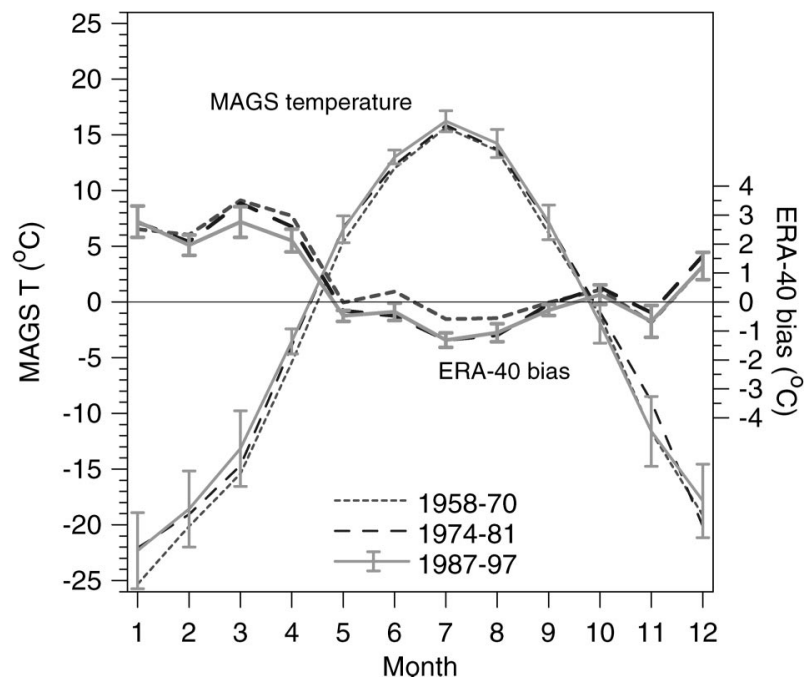

FIG. 14. Annual cycle of temperature and ERA-40 bias for three periods.

tween the skin temperature for the low-vegetation tile and the first model level, which is about $10 \mathrm{~m}$ above the surface. All three periods are very similar, so we show only the 1990s. ERA-40 has a realistic interannual variability, but it is slightly cooler in summer and warmer in winter by $2-3 \mathrm{~K}$. The model temperature bias, shown as heavy dashes, has a distinct seasonal pattern, which is similar in all years.

Figure 14 shows for three periods, the mean annual cycle of the MAGS basin temperature, and the mean bias. The standard deviations are shown for the most recent period, but they do not change significantly with time. The variability in the bias is smaller than the variability in temperature, which is largest in winter. ERA40 has a distinct warm bias in winter from December to April, peaking in March at $+3 \mathrm{~K}$. There is a sharp shift in May to a cold bias, which peaks in July at -1.5 $\mathrm{K}$. The bias has a curious warm-cold fluctuation from October to November that is about $1 \mathrm{~K}$ in magnitude (this fluctuation occurs in every year, not shown). Clearly, changes in the model surface energy balance between warm and cold seasons must be responsible for this distinct annual cycle in the model bias. The cold season warm bias may be due to the model albedo being too low (at about $15 \%$ for snow under a forest canopy), an overcorrection of the cold bias discussed in Viterbo and Betts (1999). The summer season cold bias may result from a high bias in evaporation. There is a seasonal phase lag, in that the bias stays cool till November, after the air temperature has fallen well below freezing and there is a snow cover, while the bias stays warm in spring until the air temperature is above freezing. The transition in December might be related to the ground-freezing depth, because this reduces evaporation that is coupled to liquid water in the soil, but evaporation is already low in November (Fig. 9), and the oscillation in October-November suggests that fall transition is complex.
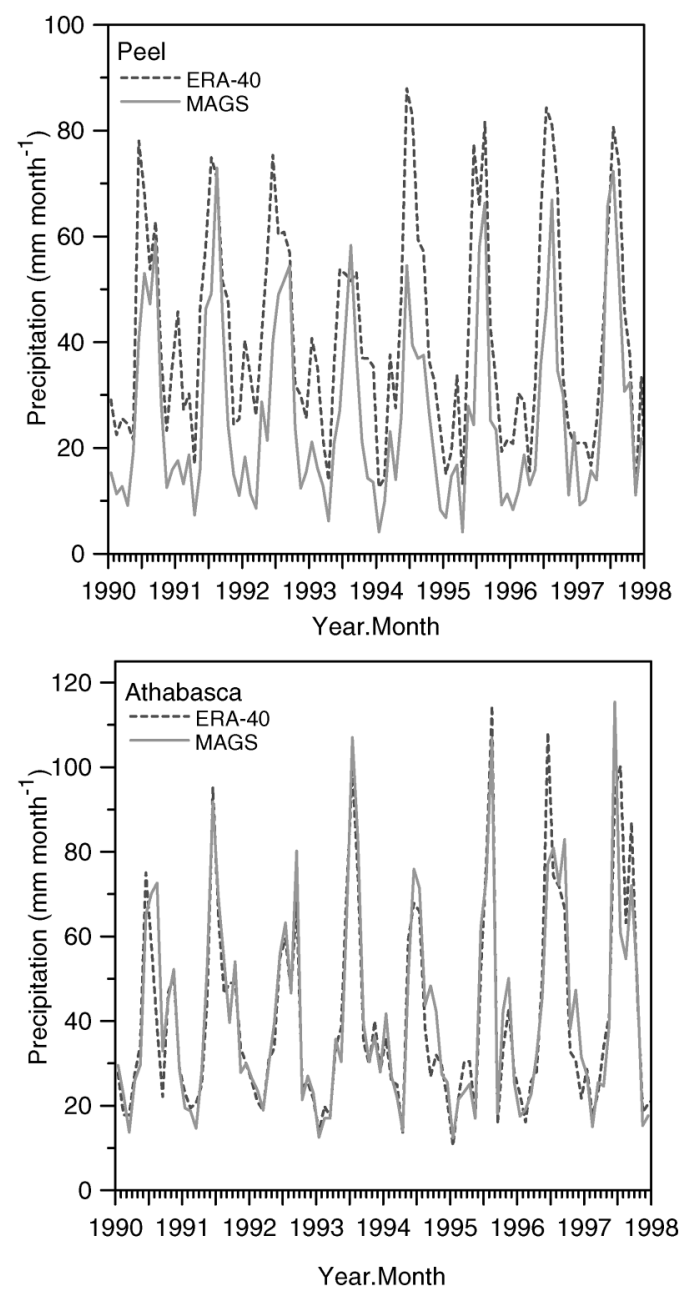

FIG. 15. Time series of precipitation for Peel River and Lake Athabasca subbasins from ERA-40 0-12-h FX and MAGS data.

We shall return to this issue when we discuss the individual sub-basins in section 4(c).

\section{Subbasin comparison of precipitation, evaporation, and temperature}

We will now show the variability across the six Mackenzie River subbasins. The Peace River is recombined into one basin (despite the large difference in elevation shown in Table 2), because our MAGS comparison data for the Peace is for the entire river basin.

\section{a. Precipitation}

Figure 15 plots, for 1990-97, ERA-40 0-12-h FX precipitation for just two of the subbasins, the Peel basin in the northwest and that of the Athabasca in the southeast, against the corresponding monthly precipitation from the MAGS observations. Model and observations 

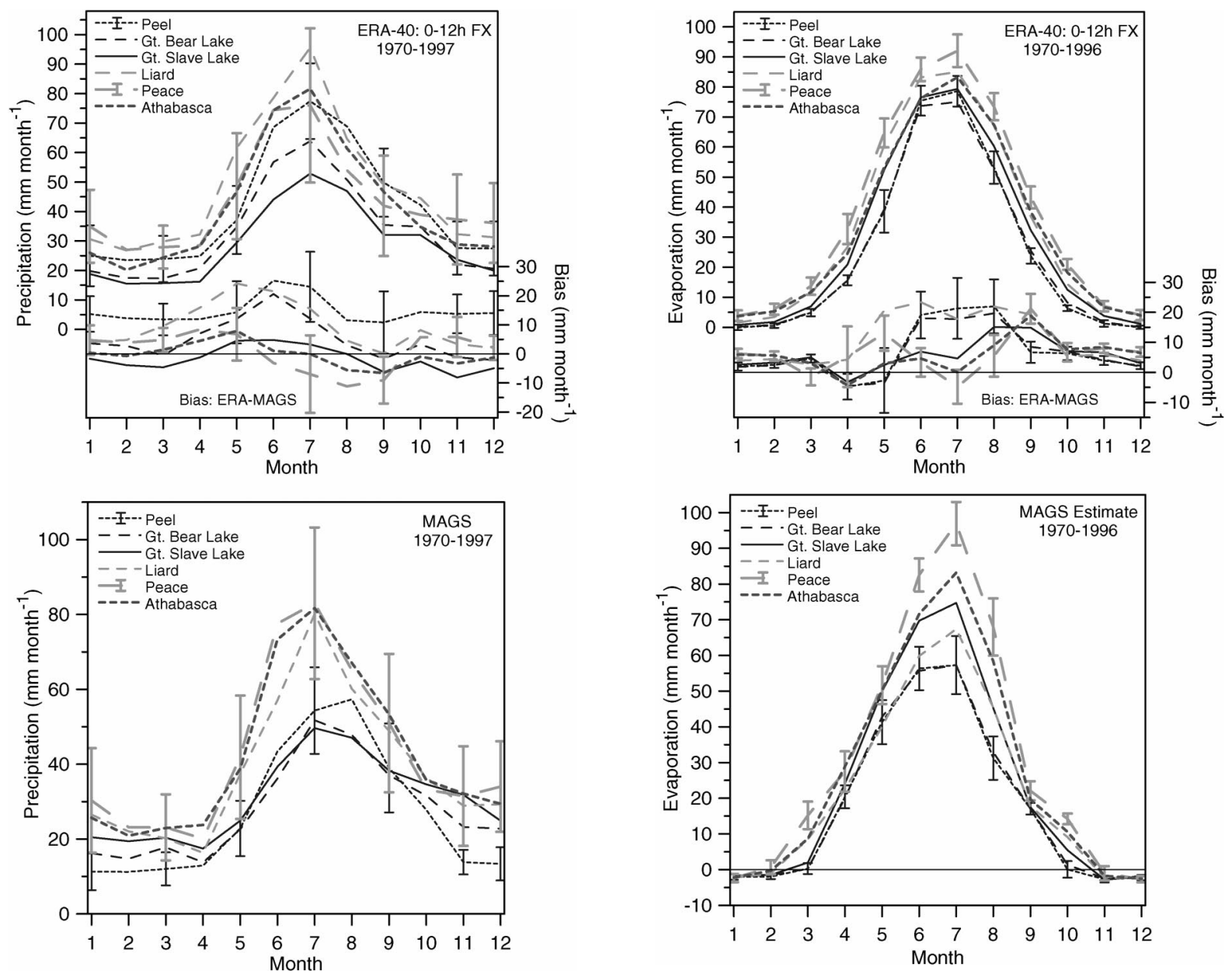

FIG. 16. Mean annual cycle of precipitation for Mackenzie subbasins from (top) ERA-40 and (bottom) MAGS estimate; with (righthand scale) model bias.

agree very well for the Lake Athabasca basin, but precipitation is considerably higher in ERA-40 for the Peel.

Figure 16 summarizes the mean annual cycle of precipitation for the six subbasins for the $28 \mathrm{yr}$ of 197097. We have omitted the first $12 \mathrm{yr}$, when there was a large spinup of precipitation. The lower panel is from the MAGS data; the representative standard deviation error bars, shown for the Peel and Peace basins, give an estimate of the interannual variability. The upper panel shows the corresponding mean from ERA-40, and, on the displaced lower right-hand scale, the bias of ERA-40 from the observations. The bias patterns show that the spring peak and late summer minimum, seen in Fig. 7, is a feature of all basins. The spring peak is earlier for the warmer basins (Lake Athabasca and Peace River) than the colder basins (Peel River and Great Bear Lake). The northwest basins (the Peel and Liard Rivers and Great Bear Lake) have generally more precipitation in ERA-40 than the MAGS observations, while the southeastern basins show primarily the seasonal ERA40 bias. However, the quality of the MAGS precipitation

FIG. 17. Mean annual cycle of evaporation for Mackenzie subbasins from (top) ERA-40 and (bottom) MAGS estimate, with (right-hand scale) model bias.

averages may not be uniform across the subbasins, because of the sparsity of data in the northwest, shown in Fig. 2. Precipitation measurement is also challenging in winter (although corrections have been applied for snowfall undercatch), and in mountainous regions. Consequently, the differences we see between ERA-40 and MAGS precipitation estimates for the northern and mountainous basins may stem from problems with (and lack of) data, rather than a bias in ERA-40. The agreement is best for the Lake Athabasca basin (apart from the seasonal bias in ERA-40), where the data coverage is reasonable.

\section{b. Evaporation}

Figure 17 compares the ERA-40 total evaporation (upper panel) with the MAGS estimate (lower panel), from Louie et al. (2002, based on the model of Morton 1983) for the six subbasins. In winter, all basins have slightly higher evaporation in ERA-40, while in summer the MAGS estimate shows more variability between ba- 
sins than ERA-40. We show, in the upper panel on the displaced right-hand scale, the bias of ERA-40 from the MAGS estimate. The bias patterns fall into the same two groups as in Fig. 16. In summer, the northwest basins with more precipitation in ERA-40 in Fig. 16 have not surprisingly higher evaporation. For the Great Slave Lake, Peace River, and Lake Athabasca basins, summer evaporation in ERA-40 is similar to the MAGS estimate, but these basins show a rise in bias in September, which may indicate the lack of a seasonal cycle in the vegetation in ERA-40. The relatively low evaporation in ERA-40 in April (about $20 \mathrm{~mm} \mathrm{month}^{-1}$ ), when the soil water is still frozen and unavailable, is an improvement on earlier versions of the model (Betts et al. 1999, 2001a). The standard deviation error bars shown for the Peel and Peace Rivers are representative of other basins also.

\section{c. Temperature}

Figure 18 shows the annual cycle of temperature for the six subbasins from ERA-40 and the MAGS observations, together with the model bias. The northern basins show little bias in both summer and winter, but the southern basins are cooler (by -2 to $-3 \mathrm{~K}$ ) in summer and relatively warmer in winter, especially the Athabasca basin (bias is $+5 \mathrm{~K}$ ). Inbetween, the Liard River basin is cool in summer and the Great Slave Lake basin is warm in winter. So, the signal seen in Fig. 14 is largely contributed by the more southern basins. The sharp fall in the bias from April to May, and from October to November (also seen in Fig. 14), is characteristic of most basins. The standard deviations shown for the Athabasca basin are representative of other basins. They show that the variability in the model systematic seasonal bias is smaller than the interannual variability, which is largest in winter. ERA-40 is reproducing most of the interannual variability in temperature, even though the mean biases differ between summer and midwinter.

At present we have no fully satisfactory explanation for the warmer model bias from December to April compared with the months from May to November. By November, the basin is snow covered and, although the ground is still freezing, evaporation for all basins is already very low (Fig. 17). The sun angle is also already low, so the cause of the transition to a warm bias between November and the months of December and January (and the October-November oscillation) is unclear. In spring, snowmelt occurs between April and May in the upper layers of the soilmelt, with a corresponding large increase in evaporation (Fig. 17), which could be responsible for the shift to a cooler bias in May. There is a large variability between basins. The basins with the warmest bias in winter (Athabasca and Peace) are those with over $90 \%$ cover of high vegetation (forests), which have the lowest albedo $(0.15$ for this vegetation class with snow underneath; Van den Hurk et al. 2000),
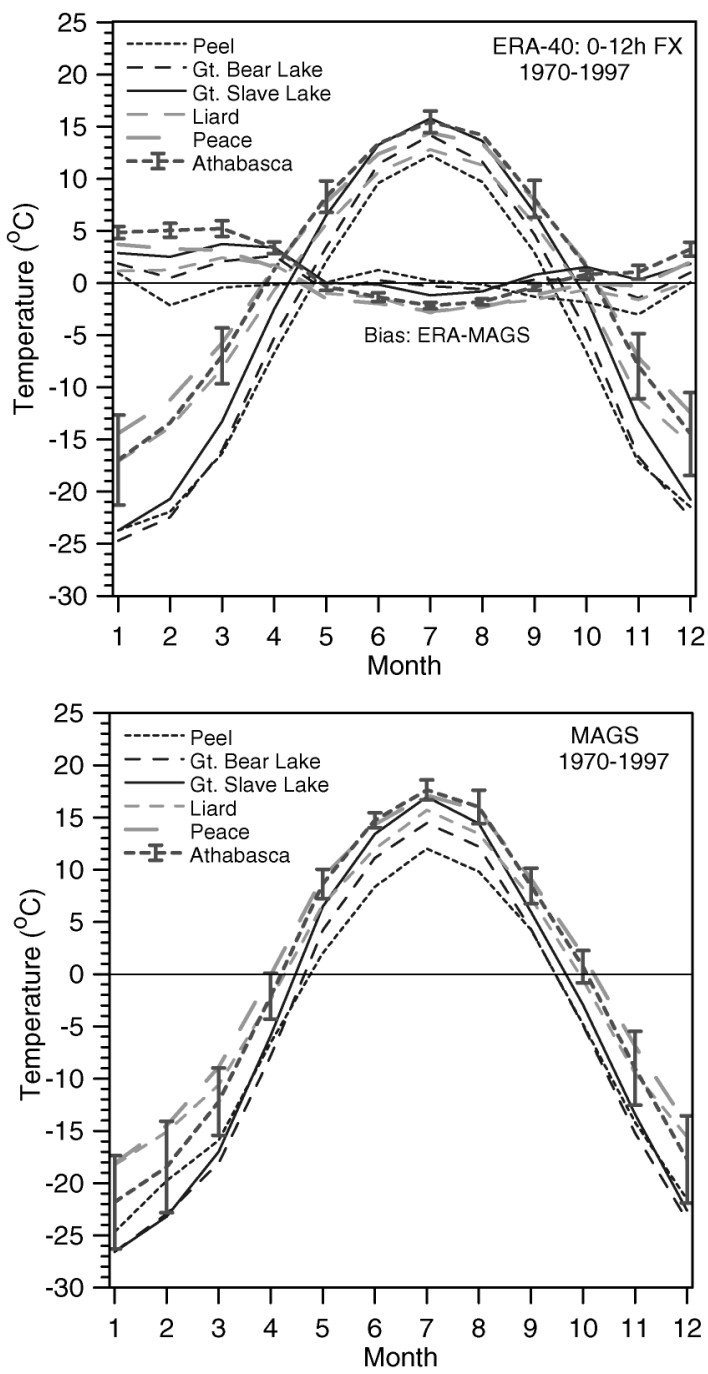

FIG. 18. Mean annual cycle of temperature for Mackenzie subbasins from (top) ERA-40 and (bottom) MAGS estimate, showing also model bias.

so it is possible that this winter albedo for the forests is too low.

\section{Soil temperature and permafrost}

The remarkable difference in deep soil temperature (for the 1-2.89-m layer in the model) across the subbasins is shown in Fig. 19. The northern basins remain largely frozen at depth even in summer, while the western basin of the Peace River, the warmest basin, only just freezes at this depth in winter. In between, the Liard basin has a very small annual cycle of deep soil temperature, because the freeze-thaw cycle introduces a large thermal inertia (Viterbo et al. 1999). This pattern is consistent with the observed climatological gradient across the Mackenzie basin, from continuous permafrost in the north, discontinuous permafrost in the central basin, and no permafrost in the south. Around freezing, 


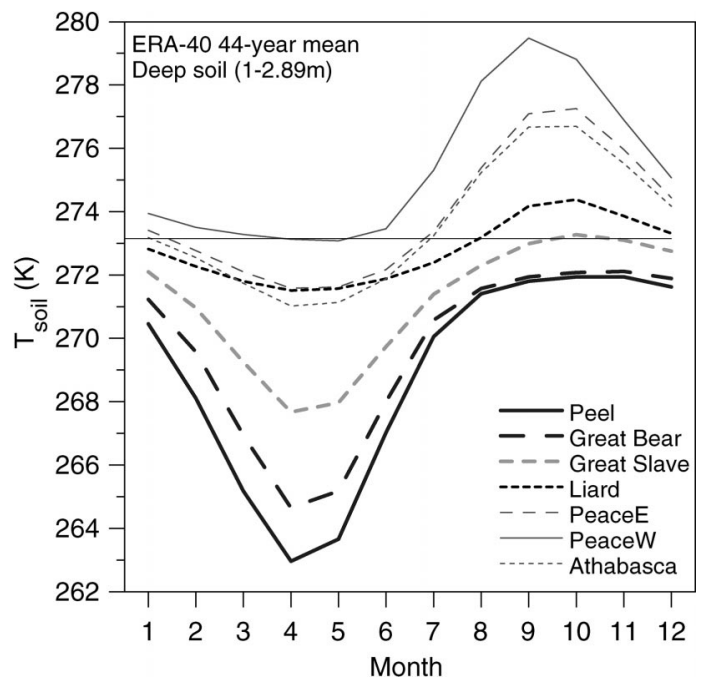

FIG. 19. Seasonal cycle of deep soil temperature in ERA-40 for subbasins.

ERA-40 uses a diagnostic function to represent the fraction of the soil water that is frozen, with a transition between $-3^{\circ}$ and $+1^{\circ} \mathrm{C}$ (Viterbo et al. 1999).

\section{Conclusions}

We have assessed the systematic biases in temperature and precipitation, and the surface water budget of ERA40 for the Mackenzie River basin by comparing monthly averages from ERA-40 with basin averages of surface observations of temperature, precipitation, evaporation, and streamflow from the Mackenzie Global Energy and Water Cycle Experiment (GEWEX) Study (MAGS). Our first finding was that the bias and spinup of precipitation in ERA-40 changes significantly over the analysis period, because of changes in the assimilated data. On an annual basis, both the bias and spinup of precipitation are correlated with the analysis increment of atmospheric total column water vapor (TCWV). The analysis removes TCWV, which reduces precipitation in the analysis cycle, and the model then spins up to restore precipitation. For the period 1974-81, when the analysis increment is near zero, the spinup is a minimum. For the same period, the mean bias is $+66 \mathrm{~mm}$, $16 \%$ of the MAGS precipitation, and within the probable error of the observations. ERA-40 has, in addition, a high bias of precipitation in spring and a low bias in fall. The monthly precipitation analysis is best for the most recent decade, when the bias of the $0-12$-h forecast precipitation is only a few percent higher than the MAGS observations, and ERA-40 represents rather well the variability of monthly precipitation.

We compared evapotranspiration from ERA-40 with a MAGS estimate, from Louie et al. (2002), derived using the semiempirical model of Morton (1983). ERA40 has about $5 \mathrm{~mm}$ month ${ }^{-1}$ more evaporation than the MAGS estimate in winter, and this bias decreases to near zero in spring, before increasing to about $15 \mathrm{~mm}$ month $^{-1}$ in summer, with a peak in the fall. Annual evapotranspiration from ERA-40 is higher than a MAGS estimate by $30 \%$. From a comparison with the water balance of the Mackenzie as a whole, we conclude that the ERA-40 evaporation is probably biased high.

A detailed comparison of the ERA-40 runoff with the Mackenzie streamflow is not possible, because the model has no river routing, and there is a long residence time for water in the Mackenzie (with its large lakes) before precipitation falling in the south reaches the mouth. The annual runoff in ERA-40 is comparable to the annual streamflow, but the interannual variability is poorly correlated. ERA-40 has two runoff peaks: April, when snowmelt runs off quickly over the frozen ground, and August, when the lowest model layer melts and reaches a soil moisture threshold, when deep drainage increases rapidly.

In the model liquid water budget (a mean for $36 \mathrm{yr}$ ), the soil water analysis increment contributes only 17 $\mathrm{mm}$ of water to the annual liquid budget (primarily in summer), which is small compared with the mean rainfall $(323 \mathrm{~mm})$ and snowmelt $(194 \mathrm{~mm})$. However, in the frozen budget, the analysis increment of snow water equivalent, with an annual mean total of $97 \mathrm{~mm}$, is not much smaller than the mean annual snowfall $(140 \mathrm{~mm})$. This is clearly an undesirable feature, which impacts the liquid budget through the snowmelt. Improvements to the model snow treatment are needed: snow melts too soon in the model, and is replaced by the snow analysis increments. The thermal properties of the snow are not well represented by a single layer. A better snow density model is also needed, because this is also used to analyze snow depth observations. It is likely that the aging of the density of the model snowpack (with a 4-day timescale) is too fast at the cold temperatures of the Mackenzie basin. For the northern basins, there are insufficient snow depth observations, so the analysis depends on climatology.

For the Mackenzie, ERA-40 has a distinct seasonal temperature bias, with a 2-3 K warm bias from December to April, and a cool bias in summer, reaching -1.5 $\mathrm{K}$ in July. This signal is most pronounced for the heavily forested southern basins. Although this is presumably related to the different model parameterizations for the winter forest with snow under tall vegetation, and to the freezing and thawing of the ground, we do not yet fully understand the details. The warm winter bias may be related to a too-low albedo for snow under tall vegetation, which was greatly reduced to correct a much larger cold bias in an earlier version of the land surface model (Viterbo and Betts 1999). The cool summer bias may reflect excess evaporation. In a comparison of the subbasins with the MAGS estimates, ERA-40 has more precipitation than the MAGS observations for the northern and western mountainous basins, but for those basins the data are sparse. For evaporation, ERA-40 has less variation across the basins than the MAGS estimate. 
Several aspects of the ERA-40 hydrology are sensitive to soil temperatures: surface runoff occurs only over frozen ground, while deep runoff depends on the lowest layer melting, and transpiration depends on liquid water in the root zone. ERA-40 appears to represent well the climatological gradient of deep soil temperature across the Mackenzie basin, from continuous permafrost in the north, to discontinous permafrost in the central basin, and no permafrost in the south.

The boreal forest and the Arctic are challenging environments for model physical parameterization. Substantial efforts at ECMWF to improve the surface model in cold regions (e.g., Viterbo and Betts 1999; Viterbo et al. 1999; Van den Hurk et al. 2000) have paid off in ERA-40 improvements relatively to ERA-15, such as a reduction of the temperature errors in winter, and the evaporation overestimation in spring. Nevertheless, deficiencies remain, and their correction is the focus of future research in the areas of snow parameterization (improved treatment of melting and snow density) and data assimilation (usage of snow cover based on remote sensing; Robinson et al. 1993).

Acknowledgments. Alan Betts acknowledges support from NASA under Grant NAS5-11578, from NSF under Grant ATM-9988618, and from ECMWF for travel. We wish to thank Robert Crawford, the MAGS data manager, and the MAGS Science team for their support of this research. Reanalysis is only possible due to the substantial "data archeology" efforts behind it. Most of the conventional data prior to 1979 is a result of the combined efforts from the National Center for Atmospheric Research and the National Centers for Environmental Prediction. Atmospheric Environment Service, Canada, provided snow depths over Canada for the period 1946-95. It is a pleasure to acknowledge the entire ERA-40 team for their assistance in (a) testing the surface model in preliminary yearly runs of the system, (b) setting up the basin model diagnostics on which this manuscript is based, and (c) providing insight into the data assimilation performance and data usage. Thoughtful remarks by the reviewers led to significant improvements in the paper.

\section{REFERENCES}

Betts, A. K., and P. Viterbo, 2000: Hydrological budgets and surface energy balance of seven subbasins of the Mackenzie River from the ECMWF model. J. Hydrometeor., 1, 47-60.

,-- _ A. C. M. Beljaars, H.-L. Pan, S.-Y. Hong, M. L. Goulden, and S. C. Wofsy, 1998: Evaluation of the land-surface interaction in the ECMWF and NCEP/NCAR reanalyses over grassland (FIFE) and boreal forest (BOREAS). J. Geophys. Res., 103, 23 079-23085.

_ M. L. Goulden, and S. C. Wofsy, 1999: Controls on evaporation in a boreal spruce forest. J. Climate, 12, 1601-1618.

_, J. H. Ball, and J. H. McCaughey, 2001a: Near-surface climate in the boreal forest. J. Geophys. Res., 106, 33 529-33 542.

, P. Viterbo, A. C. M. Beljaars, and B. J. J. M. Van den Hurk, 2001b: Impact of BOREAS on the ECMWF forecast model. $J$. Geophys. Res., 106, 33 593-33 604.

_ J. J. Ball, M. Bosilovich, P. Viterbo, Y. Zhang, and W. B. Rossow, 2003: Intercomparison of water and energy budgets for five Mississippi sub-basins between ECMWF reanalysis (ERA40) and NASA-DAO fvGCM for 1990-1999. J. Geophys. Res., 108, 8618, doi:10.1029/2002JD003127.

Cao, Z., M. Wang, B. A. Proctor, G. S. Strong, R. E. Stewart, H. Ritchie, and J. E. Burford, 2002: On the physical processes associated with the water budget and discharge of the Mackenzie Basin during the 1994/95 water year. Atmos.-Ocean, 40, 125143.

Douville, H., J.-F. Royer, and J.-F. Mahfouf, 1995: A new snow parameterization for the Meteo-France climate model. Part I: Validation in stand-alone experiments. Climate Dyn., 12, 21-35.

_, P. Viterbo, J.-F. Mahfouf, and A. C. M. Beljaars, 2000: Evaluation of optimal interpolation and nudging techniques for soil moisture analysis using FIFE data. Mon. Wea. Rev., 128, 17331756.

HYDAT, 2000: Canadian Streamflow CD-ROM. Environment Canada. [Available from Climate and Water Products Division, Environment Canada, 4905 Dufferin Street, Downsview, Ontario, Canada M3H 5T4.]

Louie, P. Y. T., W. D. Hogg, M. D. MacKay, X. Zhang, and R. Hopkinson, 2002: The water balance climatology of the Mackenzie basin with reference to the 1994/95 water year. Atmos.-Ocean, 40, 159-180.

Marsh, P., C. Onclin, and N. Neumann, 2002: Water and energy fluxes in the lower Mackenzie Valley, 1994/95. Atmos.-Ocean, 40, 245-256.

Mekis, E., and W. D. Hogg, 1999: Rehabilitation and analysis of Canadian daily precipitation time series. Atmos.-Ocean, 37, 5385 .

Metcalfe, J. R., B. Routledge, and K. Levine, 1997: Rainfall measurement in Canada: Changing observational methods and archive adjustment procedures. J. Climate, 10, 92-101.

Morton, F. I., 1983: Operational estimates of areal evapotranspiration and their significance to the science and practice of hydrology. J. Hydrol., 66, 1-76.

Robinson, D. A., K. F. Dewey, and R. R. Heim Jr., 1993: Global snow cover monitoring: An update. Bull. Amer. Meteor. Soc., 74, 1689-1696.

Rouse, W. R., 2000a: Progress in hydrological research in the Mackenzie GEWEX Study. Hydrol. Processes, 14, 1667-1685.

- 2000b: The energy and water balance of high latitude wetlands: Controls and extrapolation. Global Change Biol., 6 (Suppl. 1), $174-184$.

—_ and Coauthors, 2003: Energy and water cycles in a high latitude, north-flowing river system: Summary of results from the Mackenzie GEWEX Study-Phase 1. Bull. Amer. Meteor. Soc., 84, 73-87.

Seglenieks, F., and E. D. Soulis, 2000: Generation of square grid normals for Canada-Phase 1. Contractor's Rep. to Meteorological Services of Canada, 102 pp.

Simmons, A. J., and J. K. Gibson, 2000: The ERA-40 project plan. ECMWF ERA-40 Project Report Series No. 1, 63 pp.

Stewart, R. E., 2002: Towards understanding water and energy processes within the Mackenzie River Basin. Atmos.-Ocean, 40, 91-94.

_ - and Coauthors, 1998: The Mackenzie GEWEX Study: The water and energy cycles of a major North American river basin. Bull. Amer. Meteor. Soc., 79, 2665-2684.

— J. E. Burford, and R. W. Crawford, 2000: On the characteristics of the water cycle of the Mackenzie River basin. Meteor. Z., 9, $103-110$.

Strong, G. S., B. Proctor, M. Wang, E. D. Soulis, C. D. Smith, F. Seglenieks, and K. Snelgrove, 2002: Closing the Mackenzie basin water budget, water years 1994-95 through 1996-97. Atmos.-Ocean, 40, 159-180.

Van den Hurk, B. J. J. M., P. Viterbo, A. C. M. Beljaars, and A. K. 
Betts, 2000: Offline validation of the ERA40 surface scheme. ECMWF Tech. Memo. 295, 43 pp. [Available from European Centre for Medium-Range Weather Forecasts, Shinfield Park, Reading RG2 9AX, United Kingdom.]

Viterbo, P., and A. K. Betts, 1999: The impact on ECMWF forecasts of changes to the albedo of the boreal forests in the presence of snow. J. Geophys. Res., 104, 27 803-27810.
—_ A. C. M. Beljaars, J.-F. Mahfouf, and J. Teixeira, 1999: The representation of soil moisture freezing and its impact on the stable boundary layer. Quart. J. Roy. Meteor. Soc., 125, 24012426.

Walsh, J. E., V. Kattsov, D. Portis, and V. Meleshko, 1998: Arctic precipitation and evaporation: Model results and observational estimates. J. Climate, 11, 72-87. 